\title{
$C_{0} \mathbf{I} \cdot \mathbf{R}^{\circ} \mathbf{P} \cdot \mathrm{E} \cdot \mathrm{E}$
}

Centre Interuniversitaire sur le Risque, les Politiques Économiques et l'Emploi

Cahier de recherche/Working Paper 10-31

\section{The Effect of Monetary Policy on Credit Spreads}

\author{
Tolga Cenesizoglu
}

Badye Essid

Septembre/September 2010

Cenesizoglu: Department of Finance, HEC Montréal and CIRPÉE

tolga.cenesizoglu@hec.ca

Essid: Institute of Applied Economics, HEC Montréal and CIRPÉE

We would like to thank Michel Normandin, Simon van Norden, Georges Dionne, Pascal François, Martin Boyer, Lars Stentoft, Iwan Meier and seminar participants HEC Montréal, CIRPÉE conference and Workshop on Applied Financial Time Series. 


\begin{abstract}
:
In this paper, we analyze the effect of monetary policy on yield spreads between corporate bonds with different credit ratings over changing conditions in the economy. Using futures data on the Fed funds rate, we distinguish between expected and unexpected changes in monetary policy. We find that unexpected changes in the Fed funds rate do not have a significant effect on changes in credit spreads when we do not control for different conditions in the economy. We then distinguish between three different cycles in the economy: business, credit and monetary policy cycles. In line with predictions of imperfect capital market theories, credit spreads widen (narrow) following an unexpected monetary policy tightening (easing) during periods of poor economic and credit market conditions. Several robustness tests suggest that our results are not due to possible endogeneity problems, lack of control variables or identification methodology or different cycles.
\end{abstract}

Keywords: Business Cycle, Moody's Bond Indices, Fed Funds Rate Futures, Monetary Policy Surprises, Credit Spreads

JEL Classification: E44, E52 


\section{Introduction}

Capital market theories based on the credit view of monetary policy predict that a monetary policy shock would have a stronger impact on firms with limited access to capital markets. The exact transmission mechanism depends on the assumptions of the specific model. Models based on the balance sheet channel of monetary policy (e.g. Bernanke and Gertler (1989), Kiyotaki and Moore (1997)) argue that a firm's balance sheet serves as a collateral in financial markets with information asymmetry between borrowers and lenders. A firm with a weak balance sheet would have limited access to capital markets and would thus be more sensitive to monetary policy shocks. On the other hand, models based on the bank lending channel (e.g. Bernanke and Blinder (1992), Kashyap et al. (1993)) argue that firms with limited access to capital markets might be more bank-dependent. Since banks adjust their supply of credit with changing credit market conditions, these firms with limited access to capital markets would be more sensitive to monetary policy shocks.

Whether through the balance sheet or the bank lending channel, these models predict that firms with limited access to capital markets would not only be more sensitive to monetary policy shocks but also this effect would be more pronounced during bad times when both economic and credit market conditions deteriorate. Models based on the balance sheet channel argue that firms with weak balance sheets would become even more distressed during bad times due to decrease in demand for their services or products. Hence, these firms would find it even harder to have access to capital markets and would become even more sensitive to changes in monetary policy during bad times. On the other hand, models based on the bank lending channel argue that banks might be unwilling or unable to supply as much credit during bad times. Firms with limited access to capital markets that are more bank-dependent would become even more sensitive to changes in banks' supply of credit which in turn depends on monetary policy.

Differently from the money view of monetary policy, these theories based on the credit view also distinguish between different sources of financing (e.g. bank loans, bonds and equity) and argue that monetary policy affects the rates on these financial securities differently. There is a large literature analyzing the relation between monetary policy and equity returns or treasury bond yields. ${ }^{1}$ However, it is quite surprising to find only a small number of papers analyzing the effect of monetary policy on corporate bond yields. ${ }^{2}$ These models predict that yields on corporate bonds of firms with limited access to capital markets would be more sensitive to monetary policy shocks. Hence, yield spreads between corporate bonds of firms with similar characteristics but different levels of capital market access would increase (decrease) following an unexpected monetary policy tightening (easing) and this effect would be more pronounced during periods of poor economic and credit market conditions. In this paper, we test these

\footnotetext{
${ }^{1}$ Among others, Rigobon and Sack (2004), Bernanke and Kuttner (2005), Andersen et al. (2007) and Cenesizoglu (2008) analyze the reaction of equity returns to unexpected changes in monetary policy. Several papers including but not limited to Cook ad Hahn (1989), Kuttner (2001), Cochrane (2002), Poole et al. (2002), Berument and Froyen (2006), Demiralp and Jorda (2004), Rigobon and Sack (2004), Gurkaynak et al. (2005) and Faust et al. (2007) analyze the relation between monetary policy and bond yields. Ellingsen et al. (2004) and Andersen et al. (2007) analyze the time-varying effect of monetary policy on bond yields.

${ }^{2}$ In similar papers to ours, Kim et al. (1998) and Beckworth et al. (2009) analyze the effect of monetary policy on yields of Moody's BAA and AAA rated bond indices.
} 
implications using credit ratings as a proxy for capital market access. Our hypothesis can be summarized as follows: Yields on corporate bonds of firms with lower credit ratings would be more sensitive to unexpected changes in monetary policy and this differential effect would be more pronounced in bad times than in good times. Our paper differs from the previous studies in several ways. First of all, we distinguish between expected and unexpected changes in monetary policy using futures on the Fed funds rate. More importantly, we distinguish between different cycles in the economy and analyze the time-varying effect of monetary policy on yield spreads.

Specifically, we analyze the effect of unexpected monthly changes in the Fed funds rate on monthly changes in credit spreads between Moody's BAA and AAA, AA, A rated bond indices. Our choice to use the Fed funds rate is motivated by Bernanke and Blinder (1992) who argue that the rate is a good indicator of monetary policy. Our choice to use futures to distinguish between expected and unexpected changes in monetary policy is motivated by Kuttner (2001) who argue that Fed funds futures are good predictors of actual changes in the Fed funds rate. We use yields on bond indices rather than individual bonds to proxy for credit spreads. This choice is essential since we need a long sample that covers several cycles in the economy which is not possible with limited data on individual bonds.

We find that unexpected changes in the Fed funds rate does not have a significant effect on credit spreads when we do not distinguish between different cycles in the economy. However, the effect becomes significant when we distinguish between different phases of business, credit and monetary policy cycles. To distinguish between different phases of the business cycle, we use two ex-post and two real-time business cycle indicators. In line with the predictions of imperfect capital market theories, we find that yields on corporate bonds of firms with lower credit ratings are more sensitive to unexpected changes in monetary policy during economic recessions. We then distinguish between different phases of the credit cycle by estimating a Markov regime switching model for changes in credit spreads. We identify two distinct states corresponding to periods of widening and narrowing spreads which are related but not perfectly correlated with the phases of the business cycle. In this framework, an unexpected change in monetary policy has a significant positive effect on the credit spread between BAA and AAA rated bond indices during periods of widening credit spreads. When we distinguish between different phases of the monetary policy cycle, we also find that there is a significant positive relation between credit spreads and unexpected changes in monetary policy during periods of expansionary monetary policy. These results support the predictions of imperfect capital market theories as periods of widening spreads and expansionary monetary policy generally correspond to periods of deteriorating market conditions. Our results confirm that credit spreads increase (decrease) following an unexpected monetary policy tightening (easing) during periods of poor economic and credit market conditions.

Finally, we estimate the effect of monetary policy on credit spreads in a Markov regime switching framework where the state is jointly determined by changes in credit spreads, growth rate of industrial production and actual changes in the Fed funds rate. In this joint framework, we find that unexpected changes in monetary policy continue to have a significant positive effect on credit spreads during bad times. The effect changes sign and becomes negative during good 
times. This suggest that credit spreads narrow (widen) following an unexpected monetary policy tightening (easing) during good times. We argue that this inverse relation might be mainly due to the positive effect of an unexpected increase in the Fed funds rate on market participants' expectations about the future of the economy. Several recent papers, Romer and Romer (2000), Amato et al. (2002), Ellingsen and Soderstrom (2004), Beechey (2007) and Chun (2005), emphasize the importance of expectations for understanding the relation between monetary policy and bond yields. Romer and Romer (2000) show that commercial forecasters raise their expectations of inflation, and hence their expectations about future economic growth, following a monetary policy tightening in contrast to the predictions of more conventional monetary policy models. We find that an unexpected increase in the Fed funds rate increases market participants' inflation expectations during good times but not during bad times. Hence, credit spreads narrow (widen) following an unexpected increase (decrease) in the Fed funds rate which might be be perceived by the market participants as positive (negative) news about the future of the economy during good times.

The rest of the paper is organized as follows. Section 2 presents the related literature. Section 3 discusses the data. In Section 4, we present some preliminary analysis and summary statistics and we also discuss the possible endogeneity of unexpected changes in the Fed funds rate. We analyze the effect of monetary policy on credit spreads over the business cycle in Section 5, over the credit cycle in Section 6 and over the monetary policy cycle in Section 7. In Section 8, we discuss several other robustness tests. We analyze the time-varying effect in a joint framework and discuss possible explanations for the observed relation in Sections 9 and 10 respectively. We conclude in Section 11.

\section{Related Literature}

In this section, we first discuss the theoretical literature that motivated our empirical analysis on the effect of monetary policy on credit spreads. We then discuss the previous empirical literature that is related to our paper.

\subsection{Theoretical Background}

Classic textbook models predict that a monetary policy tightening causes an increase in the open market interest rates which in turn decreases the demand for credit and results in a fall in real economic variables such as output and employment. These so-called "money view" of monetary policy models assume that different sources of financing can be treated equally and that the capital structure and information asymmetry are irrelevant. Based on these and other similar assumptions which might not hold in reality, these classical models predict that all interest rates in the market will change in a similar fashion and hence spreads would not react to a monetary policy shock.

The theoretical motivation for our empirical analysis can be traced back to Bernanke and Blinder (1988) who are among the first to question the assumptions underlying classical textbook models of monetary policy. They develop a model of monetary policy transmission based on asymmetric information and capital structure differences between borrowers and lenders. These 
so-called "credit view" of monetary policy models distinguish between different sources of financing and hence different financial securities such as bank loans, bonds and equity. These models predict that an increase in the open market interest rate does not only decrease the demand but also the supply of credit. Hence, according to these models, rates on different financial securities will change differently following a monetary policy shock. In addition, these models predict that the effect of monetary policy on spreads also changes with business and credit market conditions. The credit view of monetary policy transmission argues that the monetary policy affects the real economy through two channels, balance sheet and bank lending channels. The balance sheet channel focuses on the informational asymmetry between borrowers and lenders whereas the bank lending channel focuses mostly on lending activities of banks and bank-dependent borrowers.

Models based on either of these two channels have both time-series and cross-sectional predictions on the effect of monetary policy on credit spreads. According to models of Bernanke and Gertler (1989) and Kiyotaki and Moore (1997) based on the balance sheet channel, there is informational asymmetry between borrowers and lenders. Borrowers generally know their financial situations and the profitability of their projects better than lenders. Due to this informational asymmetry, borrowers' assets do not only serve as means of production but also as collateral for external financing. An unexpected tightening of monetary policy weakens the balance sheet or the net worth of the borrower by not only increasing the cost of debt but also by decreasing cash flows from its assets due to weakened aggregate demand. The effect of an unexpected tightening of monetary policy would be even stronger during recessions and periods of already rising interest rates. In terms of the cross-sectional predictions of these models, financially constrained firms with already weak balance sheets and low net worth would be more adversely affected by a monetary policy tightening than others. On the other hand, models of Bernanke and Blinder (1992) and Kashyap et al. (1993) based on the bank lending channel assume that banks' lending activities are negatively affected following a worsening of their balance sheets due to an unexpected monetary policy tightening. Hence, they are either unable or unwilling to lend as much as before. The supply of credit by banks decreases even further during periods where their balance sheet are already weak such as during recessions and periods of increasing interest rates. In terms of the cross-sectional predictions, firms which have limited access to capital markets and depend on banks for external financing will be more strongly affected by a tightening monetary policy. For example, firms with low credit ratings might find it relatively more difficult to raise debt in financial markets and hence might be more adversely affected following a monetary policy tightening.

\subsection{Empirical Background}

Our paper is closest in spirit to Gertler and Gilchrist (1994). They test the time-series and cross-sectional implications of imperfect capital market theories using firm size as a proxy for capital market access, sales and inventories as measures of firm performance and GNP growth as a measure of business conditions. In line with the predictions of imperfect capital market theories, they find that sales and inventories of small manufacturing firms exhibit sharper declines following a monetary policy tightening in bad times. They also show that the effect of monetary policy is significantly different for small firms between periods of economic growth 
and slowdown, but not for large firms. Our paper also draws on several other empirical studies that analyze the relation between credit spreads and monetary policy. Kim et al. (1998) analyze the effect of monetary policy over monetary easing and tightening periods. They use several measures of monetary policy including Romer dates, the Boschen and Mills index, and the first difference in the Fed funds rate and they find that increases in the Fed funds rate significantly raise the yield on Baa bonds absolutely and relative to yield on Aaa bonds. They argue that the asymmetric effect of monetary policy might be due to the credit channel of monetary policy. Avramov et al. (2007) attempt to explain credit spreads in corporate bonds using a structural model with structural variables. As an additional robustness test, they include a dummy variable for expansionary and contractionary monetary policy to control for the effect of market-wide liquidity on changes in credit spreads. They find that the dummy variable for monetary policy is significant only for high grade bonds and expansionary (contractionary) policy decreases (increases) credit spreads. Recently, Beckworth et al. (2009) analyze the effect of monetary policy shocks on credit spreads. Using money supply as an indicator of monetary policy in a VAR framework, they find that an unexpected increase in the money supply results in a decrease in the spreads between Moody's BAA and AAA bond yields.

\section{Data}

In this section, we briefly describe our data on credit spreads and Fed funds futures as well as the methodology used to extract expected and unexpected monthly changes in the Fed funds rate. We use unexpected changes in the Fed funds rate as an indicator of monetary policy. Our choice is motivated by Bernanke and Blinder (1992) who argue that the Fed funds rate is a good indicator of monetary policy. Following Kuttner (2001), we use monthly data on 30 day Fed funds futures traded on the Chicago Board of Trade (CBOT) to distinguish between the expected and unexpected components of changes in the Fed funds rate. Gurkaynak et al. (2007) find that the Fed funds futures is the best predictor of future Fed funds rates among other market-based measures. The data on 30 day Fed funds futures is available between May 1989 and December 2008 from Datastream, which also determines our sample period. The contracts are cash settled against the average daily Fed funds overnight rate where the average is calculated over all calendar dates of the delivery month by carrying the rate from the last business day for weekends and holidays. The implied Fed funds rate is 100 minus the price quote. The unexpected change in the Fed funds rate in month $t$ is the difference between the average realized Fed funds rate in month $t$ and the rate predicted by the Fed funds futures on the last day of the previous month:

$$
U_{t}=\frac{1}{D_{t}} \sum_{d=1}^{D_{t}} i_{t, d}-f_{t-1, D_{t-1}}^{1}
$$

where $i_{t, d}$ is the Fed funds rate on day $d$ of month $t$ and $D_{t}$ is the number of total calendar days in month $t$. The Fed funds rate implied by the price of the one month Fed funds futures on the last day $\left(D_{t-1}\right)$ of previous month $(t-1)$ is denoted by $f_{t-1, D}^{1}$. The expected change in the Fed funds rate in month $t$ is the difference between the implied rate from the futures price and the actual Fed funds rate on the last day of month $t-1$ :

$$
E_{t}=f_{t-1, D_{t-1}}^{1}-i_{t-1, D_{t-1}}
$$


The sum of the unexpected and expected changes in the Fed funds rate is not the actual change but rather the difference between the average Fed funds rate in month $t$ and the implied rate on the last day of month $t-1$. The actual change in month $t, A_{t}$, is the difference between the Fed funds rates on the last day of month $t$ and $t-1$ :

$$
A_{t}=i_{t, D_{t}}-i_{t-1, D_{t-1}}
$$

Monthly average yields on Moody's seasoned BAA, A, AA and AAA rated bonds for the sample period between May 1989 and December 2008 are available to us from the Global Financial Data. Credit spreads are defined as the difference between the yield on BAA rated bonds and the yields on A, AA and AAA rated bonds, respectively. In this paper, we choose to use bond indices to capture credit spreads rather than individual bonds for several reasons. First of all, data on individual bonds is available only for a relatively short period of time. Since we focus on the time-varying effect of unexpected changes in monetary policy on credit spreads, a sample period which includes at least several macroeconomic cycles is absolutely necessary for our analysis. Secondly, we believe that bond indices are more suitable than individual bonds to analyze the effect of a systematic factor such as the monetary policy. Finally, in addition to the articles mentioned in Section 2.2, David (2008), Davies (2008) and Bevan and Garzarelli (2000) use Moody's bond indices as measures of aggregate credit spreads.

\section{Preliminary Analysis}

In this section, we present some preliminary results on the effect of monetary policy on credit spreads based on an empirical specification where we do not distinguish between different cycles in the economy. Based on imperfect capital market theories, we then argue that the insignificant relation between monetary policy and credit spreads might be mainly due to the assumption of a constant relation between the two variables. To show that our results are not due to a systematic bias of Fed funds futures over different market conditions in predicting the actual change in the Fed funds rate, we present some basic summary statistics for these two variables over different phases of the business, credit and monetary policy cycles. Finally, we discuss the possibility of an endogenous relation between unexpected changes in monetary policy and changes in credit spreads.

\subsection{The Effect of Monetary Policy on Credit Spreads}

We first analyze the effect of unexpected changes in the Fed funds rate on monthly changes in credit spreads. For several reasons, we choose to focus on unexpected changes in the Fed funds rate rather than actual or expected changes. First of all, the expected component of actual changes in the Fed funds rate must have already been incorporated in credit spreads. The literature agrees on the fact that it is not the expected but the unexpected component which has a significant impact on returns in financial markets. Secondly, as we discuss below in further detail, expected and actual changes in the Fed funds rate are closely related to changing economic conditions and might suffer more from an endogeneity problem than unexpected changes. More importantly, we use actual and expected changes in the Fed funds rate to define monetary policy cycles in the economy. We also focus on changes in credit spreads rather than levels of credit 
spreads. Avramov et al. (2007) argue that changes in credit spreads capture important aspects of fixed income markets and the difference between levels and changes in credit spreads is similar to the difference between equity prices and returns. Fort the rest of the paper, the reader should keep in mind that we consider changes in credit spreads in basis points even though the word "changes" is dropped.

To analyze the overall effect of unexpected changes in monetary policy on credit spreads where we do not distinguish between different macroeconomic cycles, we estimate a simple empirical specification for changes in each credit spread separately via OLS with Newey-West heteroskedasticity and autocorrelation consistent (HAC) standard errors:

$$
\Delta \text { Spread }_{t}=\beta_{0}+\beta_{1} U_{t}+\varepsilon_{t}
$$

where $\Delta$ Spread $_{t}$ is the monthly credit spread change in month $t$. Table (1) presents our empirical results. Although insignificant, the positive coefficient estimates suggest that credit spreads increase following an unexpected monetary policy tightening in line with predictions of imperfect capital market theories. The insignificant relation between monetary policy and credit spreads are based on a simple constant parameter model which is not able to account for any state-dependent or time-varying effect. Imperfect capital market theories do not only have crosssectional predictions for the effect of monetary policy on the cost of borrowing for firms with different characteristics but also time-series predictions on how this effect might change with changing market conditions. To this extent, we first present some summary statistics on credit spreads and unexpected changes in the Fed funds rate as well as the relation between these two variables over business, credit and monetary policy cycles in the economy.

\subsection{Summary Statistics over Different Cycles}

We start with summary statistics over the business cycle. Table (2) presents summary statistics for unexpected changes in the Fed funds rate and credit spreads during recessions and expansions defined based on NBER dates. These summary statistics suggest that the market participants, on average, overpredict actual changes in the Fed funds rate both in recessions and expansions. They are more uncertain about the actual change in the Fed funds rate in recessions as suggested by higher standard deviation in recessions. However, the unexpected change is not significantly different than zero either in recessions or in expansions. The average change in credit spreads is relatively large and positive in recessions compared to a small and negative change in expansions. In other words, credit spreads widen during recessions with a fast pace whereas they narrow with a relatively slower pace during expansions. The credit spread between BAA and AAA-rated bonds increases faster in recessions than the spread between BAA and A-rate bonds. On the other hand, the spread between BAA and AAA-rated bonds narrows with a slower pace than the spread between BAA and A-rated bonds. These results are in line with those in Fama and French (1989) who find that credit spreads widen when economic conditions deteriorate. Furthermore, the change in credit spreads is more volatile in recessions than in expansions and this effect is strongest for the spread between BAA and AAA-rated bonds. These results suggest that different credit spreads have different sensitivities to changing economic conditions. More importantly, the correlations between credit spreads and unexpected changes in the monetary policy are positive and large during recessions and practically zero in 
expansions. This suggests that the relation between these two variables changes dramatically over the business cycle in line with predictions of imperfect capital market theories.

We now turn our attention to summary statistics over the credit cycle. In this section, we use an ad hoc definition of the credit cycle based on the sign of the monthly change in credit spreads. Specifically, if the change in a given credit spread in a given month is positive, we refer to this month as a period of widening for this specific credit spread. For the purposes of calculating the summary statistics of unexpected changes in the Fed funds rate over credit cycles, we define the periods of widening credit spreads if two of the three credit spreads increase during a given month. In Section 6, we use a more intuitive definition of the credit cycle based on a Markov regime switching framework. Table (3) presents summary statistics on monthly credit spreads over the credit cycle. First of all, there is no systematic bias in unexpected changes over credit cycles. Market participants underestimate the actual change in the Fed funds rate over periods of narrowing and widening credit spreads. Both the mean and volatility of credit spreads are higher (in absolute value for the mean) during periods of widening credit spreads. More importantly, the correlation between unexpected changes in the Fed funds rate and credit spreads is also higher during periods of widening, except for the credit spread between BAA and A rated bonds.

Finally, we discuss summary statistics over the monetary cycle defined as expansionary, contractionary and neutral cycles based on the sign of the actual change in the Fed funds rate. Specifically, if the Fed decides to increase (decrease) the rate in a given month, it is considered a period of contractionary (expansionary) monetary policy. If the Fed funds rate remains unchanged in a given month, it is considered a period of neutral monetary policy. In Section 7 , we use several other definitions of the monetary policy cycle. Table (4) presents summary statistics on monthly credit spreads over the monetary policy cycle. Although insignificant, the Fed funds futures tend to underestimate the actual change in the Fed funds rate more during periods of expansionary monetary policy than during periods of contractionary monetary policy. Overall, the Fed funds futures provides an unbiased predictor of actual changes in the Fed funds rate. During periods of expansionary monetary policy, credit spreads tend to increase and the correlation between unexpected changes in the Fed funds rate and credit spreads is positive. During periods of contractionary monetary policy, credit spreads also tend to increase but with a relatively slower pace and the correlation is negative. Finally, during periods of neutral monetary policy, credit spreads tend to remain unchanged and the correlation is positive.

These simple summary statistics suggest that the relation between monetary policy and credit spreads changes with respect to different cycles in the economy. In the rest of the paper, we analyze this time-varying effect of monetary policy on credit spreads. Before proceeding to our empirical results, we discuss the possible endogeneity of our measure of unexpected changes in monetary policy in the next section.

\subsection{Endogeneity of Unexpected Changes in the Fed Funds Rate}

One of the key assumptions underlying the validity of our empirical results is the exogeneity of explanatory variables in our empirical specifications. There are several reasons why this assumption might be violated for the variable of interest, unexpected changes in the Fed funds 
rate. First of all, the Fed might be contemporaneously responding to credit spreads. Secondly, credit spreads and the Fed might be reacting jointly and contemporaneously to new economic information. Here, we discuss and present some evidence for the exogeneity of unexpected changes in the Fed funds rate.

We start with the possibility of a contemporaneous response of monetary policy to credit spreads. Although such responses of monetary policy to credit spreads are not common, one such response was observed during the recent financial crisis in 2007 and 2008 when the Fed decided to decrease the rate following disruptions in financial markets. In his speech on January 2008, Mishkin (2008) argues the importance of monetary policy that takes into account variables indicating stress in financial markets in addition to variables of a simple Taylor rule (Taylor (1993)). Among such variables indicating stress in financial markets are changes in the level and volatility of credit spreads. McCulley and Toloui (2008) and Taylor (2008) propose modified Taylor rules that decrease the Fed funds rate when credit spreads increase even if inflation expectations and output gap remain unchanged. Cúrdia and Woodford (2009) analyze the usefulness of such monetary policy rules in a simple DSGE model with credit frictions and argue that these modified monetary policy rules can improve the equilibrium responses of economic variables to financial shocks.

A monetary policy rule that takes credit spreads into account suggests that the Fed must be contemporaneously responding to credit spreads. This in turn implies that the actual and expected changes in the Fed funds rate are determined by, hence endogenous to, credit spreads. However, these suggested monetary policy rules do not necessarily imply the endogeneity of unexpected changes. Thus, unexpected changes might not suffer as much from the endogeneity problem as actual and expected changes. To this end, we discuss several empirical results from our preliminary analysis. The first evidence is the low and insignificant correlation between unexpected changes in the Fed funds rate and credit spreads presented in Table (1). These results suggest that unexpected changes are not endogenous at least in the whole sample. The second evidence is from the estimation of the empirical specification in Equation (4) for the sample period between January 2007 and December 2008. The idea is that the Fed might have been paying closer attention to credit spreads during the financial crisis. Our results indicate an insignificant relation between credit spreads and unexpected changes in the Fed funds rate.

We now turn our attention to the joint and contemporaneous reaction of monetary policy and credit spreads to new economic information. Unexpected bad economic news might result in an increase in credit spreads and make the Fed more likely to decrease the rate. To this extent, we analyze the reaction of unexpected changes in the Fed funds rate and credit spreads to economic news. We first use MMS data to extract economic news for the same variables considered in Bernanke and Kuttner (2005). Since the MMS data is not available to us for the period of our whole sample, we then analyze the reaction of unexpected changes in the Fed funds rate to changes in the same macroeconomic variables.

The economic news is defined as the difference between the announced value for the variable and the median survey expectation extracted from the MMS data. We then standardize the news variable by dividing it by its in-sample standard deviation. Table (5) presents the coefficient estimates from a regression of unexpected changes in the Fed funds rate or credit spreads on 
economic news extracted from the MMS data between August 1989 and August 2005. Similar to Bernanke and Kuttner (2005), we also find that the Fed might be reacting to news about PPI and Employees on Nonfarm Payrolls. However, credit spreads do not react significantly to news about these two variables. The only new variable that has a significant effect on credit spreads is the Headline CPI. These results suggest that unexpected changes in the Fed funds rate and credit spreads do not react jointly and contemporaneously to news about the same macroeconomic variables.

We next estimate a regression of unexpected changes in the Fed funds rate or credit spreads on changes in CPI, PPI, Employees on Nonfarm Payrolls, Industrial Production and Retail Sales with and without Motor Vehicles. For most of these variables, a random walk model provides reasonable one-month ahead forecasts. Hence, changes in these variables can also be considered as news about these variables. The data is available to us from the Federal Reserve Bank of St. Louis between February 1992 and December 2008. The data period is imposed on us by the availability of the data on Retail Sales. Table (6) presents our empirical results. Several news variables have a significant effect on credit spreads. However, unexpected changes in the Fed funds rate do not react significantly to news about any of these variables. These results provide further evidence that unexpected changes in the Fed funds rate and credit spreads do not react jointly and contemporaneously to news about the same macroeconomic variables. Overall, our results suggest that unexpected changes in the Fed funds rate are not endogenous to credit spreads, at least during our sample period.

\section{The Effect of Monetary Policy on Credit Spreads over the Business Cycle}

As discussed in Section 2, imperfect capital market theories predict that firms with low credit ratings should be more sensitive to unexpected changes to monetary policy and this effect should be more pronounced when economic conditions are deteriorating. In other words, credit spreads should increase following an unexpected monetary policy tightening in recessions. Our summary statistics over NBER recessions confirm that the correlation between credit spreads and monetary policy is positive in recessions in line with the theoretical predictions. In this section, we extend our analysis and test these implications using four different measures to proxy for changing business conditions. We first discuss our ex-post and real-time measures of business conditions. We then present our empirical results and discuss the possible endogeneity of our business cycle indicators. Finally, we analyze the robustness of our results to industry-specific credit spreads and control variables.

\subsection{Ex-post Measures of Business Cycle}

The first ex-post measure is a dummy variable that takes the value 1 in month $t$ if the economy is in a recession as defined by the NBER and zero otherwise. The second one is the monthly growth rate of industrial production based on the latest vintage of industrial production index available. These two measures are considered ex-post because they would not have been available to market participants in real-time. For the first measure of business conditions, there is 
a significant delay between the start or the end of a recession and the period when the NBER announces that the economy has been in a recession. For the second measure, we used revised data rather than real-time data that the market participants would have had access to.

\subsection{Real-time Measures of Business Cycle}

As discussed above, the data on industrial production gets revised to reflect more accurate estimates as additional information arrives like many other macroeconomic variables. However, market participants would not have had access to this revised data in real-time when forming their expectations of a recession. Hence, for the first real-time measure, we estimate recession probabilities based on real-time vintages of industrial production. To do so, we model the growth rate of real-time industrial production as a two-state Markov regime switching model. The mean and variance of the industrial production growth rate can take different values depending on the state. Specifically, our model for the growth rate of industrial production can be written as follows:

$$
\Delta \ln \left(I P_{t}\right)=\alpha_{S_{t}}+\omega_{S_{t}} \epsilon_{t}
$$

where $\epsilon_{t}$ is independent and identically distributed normal random variables with zero mean and unit variance, $\alpha_{S_{t}}$ and $\omega_{S_{t}}$ are the mean and standard deviation of the growth rate of industrial production, and $S_{t}$ is the state variable that can take two values, zero and one. The state in which the growth rate of industrial production is smaller can be considered as the recession state and we arbitrarily assign the label zero for the recession state.

Real-time data on monthly industrial production index for different vintages is available to us from the Federal Reserve Bank of St. Louis. The nature of the real-time data forces us to distinguish between two different approaches to calculate the probabilities of recession in a given month. Consider the first observation in our sample, May 1989. The latest data that would have been available to market participants at the end of May 1989 is the industrial production for April 1989. To obtain probabilities of recession, we estimate the Markov regime switching model in Equation (5) for the sample period between January 1950 and April 1989 as it would have been available to market participants in May 1989. One should note that the industrial production for May 1989 would have only been available with a one month delay in June 1989. The filtered probability of the recession state calculated in May 1989 is based on industrial production data between January 1950 and April 1989. One can also consider forming a one-month ahead forecast of the recession probability based on estimated transition probabilities.

Specifically, let $\widehat{p}_{00}$ and $\widehat{p}_{11}$ denote the transition probabilities of the two-state Markov chain estimated from the Markov regime switching model in Equation (5) using real-time data available on May 1989 for the sample period between January 1950 and April 1989. Then, the two probabilities of recession are

$$
\begin{aligned}
& \operatorname{Prob}_{1, \text { May 1989 }}=\operatorname{Prob}\left(S_{t}=0 \mid I P_{\text {April 1989|May 1989 }}, \ldots, I P_{\text {January 1950|May 1989 }}\right) \\
& \operatorname{Prob}_{1, \text { May } 1989}^{f}=\operatorname{Prob}_{1, \text { May } 1989} \widehat{p}_{00}+\left(1-\operatorname{Prob}_{1, \text { May } 1989}\right)\left(1-\widehat{p}_{11}\right)
\end{aligned}
$$

where $I P_{\text {April } 1989 \mid \text { May } 1989}$ denotes the industrial production in April 1989 as it would have been available in May 1989. To obtain recession probabilities for June 1989, we use the real-time 
data for industrial production between January 1950 and May 1989 as it would have been available in June 1989. We continue in this fashion using an expanding window of observations to obtain recession probabilities for our sample until December $2008 .^{3}$ Although we consider these two probabilities of recession in our analysis, we only present our results based on the first one $\left(\operatorname{Prob}_{1, t}\right)$ for the rest of the paper. ${ }^{4}$

Our approach to obtain real-time recession probabilities is based on a single indicator of economic activity, i.e. industrial production. One can also consider estimating a similar Markov regime switching model for a vector of several indicators of economic activity including but not limited to industrial production. Such an approach is implemented by Chauvet and Piger (2008) using dynamic four factor Markov switching model for changes in industrial production, personal income, employees on nonfarm payrolls and manufacturing. These probabilities $\left(\operatorname{Prob}_{2, t}\right)$ are available to us from Jeremy Piger's website.

Figure (1) presents the two real-time probabilities of recession as well as NBER recessions and the growth rate of industrial production based on revised data. It is easy to see that two realtime recession probabilities are quite similar although the recession probabilities based on four indicators of economic activity are much smoother than those based only on industrial production. Not surprisingly, both recession probabilities increase and approach one during NBER recessions whereas they are close to zero during NBER expansions.

\subsection{Empirical Results}

In this section, we present our empirical results on the effect of unexpected changes in the Fed funds rate on credit spreads over changing business conditions proxied by the two ex-post and two real-time measures discussed above. To this extent, we estimate the following empirical specification for each credit spread separately via OLS with HAC standard errors:

$$
\Delta \text { Spread }_{t}=\beta_{0}+\beta_{1} U_{t}+\beta_{2} B C I_{t}+\beta_{3}\left(U_{t} \times B C I_{t}\right)+\varepsilon_{t}
$$

where $B C I_{t}$ is one of the four business cycle indicator (BCI) in month $t$. The interaction term allows us to analyze the marginal effect of unexpected changes in the Fed funds rate on credit spreads during periods of economic slowdown. Before discussing our results, we should first note that the NBER recession dummy variable and the two real-time measures are similar in the

\footnotetext{
${ }^{3}$ We also considered real-time probabilities of recession based on a rolling window of real-time observations. Our approach based on a rolling window of observations can be summarized as follows: To estimate the real-time probability of recession in May 1989, we estimate the Markov regime switching model in Equation (5) using data between between January 1950 and April 1989 as it would have been available to market participants in May 1989. Hence, the real-time recession probabilities based on expanding and rolling windows of observations for May 1989 are identical. To estimate the real-time probability of recession in June 1989, differently from an expanding window approach, we drop the January 1950 observation and estimate the model using data between February 1950 and May 1989 as it would have been available to market participants in June 1989. We continue in this recursive fashion using a rolling window of observations. Our results based on a rolling window of observations are qualitatively and quantitatively very similar to those based on an expanding window of observations and are available from the authors upon request. We also considered a shorter window of rolling and expanding observations and our results do not change significantly.

${ }^{4}$ Our results do not change significantly when we consider the forecasted probability second probability $\left(\operatorname{Prob}_{1, t}^{f}\right)$.
} 
sense that a higher number represents either a recession or a higher probability of recession. On the other hand, the other ex-post measure of business conditions, namely the growth rate of industrial production, is different in the sense that a positive number represents economic growth and a negative number represents economic slowdown. Our preliminary results discussed in Section 2 suggest that credit spreads generally widen during periods of economic slowdown. Hence, we expect positive coefficient estimates for the NBER recession dummy variable and the two real-time measures and negative coefficient estimates for the growth rate of industrial production as a measure of business conditions.

Table (7) and Table (8) present empirical results using ex-post and real-time measures of business conditions, respectively. The results are quite similar whether we use ex-post or real-time measures of business conditions and can be summarized as follows: As expected, credit spreads generally widen during periods of economic slowdown. More importantly, unexpected changes in the Fed funds rate has a positive and significant effect on credit spreads during periods of economic slowdown although the effect is insignificant when we do not distinguish between different economic conditions. The effect is strongest for the credit spread between BAA and AAA rated bonds and decreases almost monotonically for the two other credit spreads. Furthermore, the results are not as significant for the empirical specification with real-time recession probabilities from Chauvet and Piger (2008). This might be due to the fact that the relation between credit spreads and industrial production is stronger than the relation between credit spreads and other additional variables used by Chauvet and Piger (2008). These results are not only significant statistically but also economically. Consider the empirical specification with the NBER recession dummy variable for which the economic interpretation of the coefficient estimates is the easiest. A 10 basis point (approximately one standard deviation) unexpected increase in the Fed funds rate results in an additional increase of 2.8 basis points in the credit spread between BAA and AAA rated bonds during NBER recessions. These results suggest that firms with low credit ratings are more sensitive to unexpected changes in monetary policy during recessions in line with predictions of imperfect capital markets.

\subsection{Endogeneity of Business Cycle Indicators}

The validity of our empirical results depends on the assumption that the error terms in our empirical specifications are orthogonal to the explanatory variables. In our preliminary analysis, we provided some empirical evidence against the endogeneity of unexpected changes in the Fed funds rate. In this section, we first test the endogeneity of our business cycle indicators. We then analyze the effect of unexpected changes in the Fed funds rate on credit spreads over the business cycle in a two stage least squares (TSLS) framework. Finally, we employ forecasted instead of contemporaneous business cycle indicators to alleviate the endogeneity problem.

In this section, we consider the endogeneity of the two ex-post measures of business conditions as they are observable variables that can be regressed on instrumental variables. On the other hand, the real-time measures are filtered probabilities of latent state variables and, hence, they cannot be directly regressed on other variables. As discussed below, to analyze the effect of possible endogeneity of real-time measures on our empirical results, we use forecasted recession probabilities instead of contemporaneous recession probabilities so as to eliminate any 
contemporaneous relation between credit spreads and real-time measures. The endogeneity of business cycle indicators also implies the endogeneity of the interaction terms in Equation (7). Hence, we consider the endogeneity of both the business cycle indicators and the interaction terms.

We first focus on the instrumental variables used in this paper. These variables must be uncorrelated with the dependent variable, i.e., credit spreads, and correlated with the variables believed to be endogenous, i.e. the business cycle indicators and the interaction between the business cycle indicators and the unexpected changes in the Fed funds rate. To this extent, we use lagged changes in employment numbers, log industrial production, consumer price index and housing starts and the interaction terms between these variables and unexpected changes in the Fed funds rate as instrumental variables. Tables (9) and (10) present the relation between credit spreads, endogenous variables and instrumental variables. Our results suggest that the instrumental variables are correlated with endogenous variables but uncorrelated with credit spreads. We also consider the possibility of weak instruments. To this extent, Table (10) also presents the Cragg-Donald statistic, $g_{m i n}$, for weak instruments discussed in Stock and Yogo (2005) along with two measures of the maximal relative bias of TSLS estimates with respect to OLS estimates. The Cragg-Donald statistic examines the null hypothesis that the instruments are weak and the critical values for this test statistic are tabulated in Stock and Yogo (2005) and depend on the maximal relative bias of TSLS estimates with respect to OLS estimates. For example, if we are willing to accept a maximal relative bias of 0.30 , the Cragg-Donald statistics suggest that our instruments are not weak. However, at a maximal relative bias of 0.05 , our instruments become weak for both business cycle indicators. The estimates of maximal relative bias are 0.59 and 0.06 for the NBER dummy variable and 0.16 for the growth rate of industrial production. Hence, our results suggest that our instruments might be weak or not depending on the maximal relative bias.

To test for the endogeneity of the business cycle indicators, we use the Durbin-Wu-Hausman (DWH) tests of endogeneity discussed in Staiger and Stock (1997). These statistics test the exogeneity of the variables believed to be endogenous by checking for a statistically significant difference between the OLS and TSLS estimates of the coefficients on these variables. A statistically significant test statistic rejects the null hypothesis that the variables are exogenous. Staiger and Stock (1997) suggest three DWH statistics and argue that the $F_{D W H, 3}$ provide the correct test when instruments are weak. For completeness, Table (11) presents all three DWH statistics suggested in Staiger and Stock (1997). Our results suggest that the growth rate of industrial production is not possibly endogenous whereas the same does not hold true for the NBER dummy variable. However, one should keep in mind that we estimate a linear probability model for the NBER dummy variable instead of a probit or a logit model. Although a probit or a logit model might provide a better fit for the NBER dummy variable, the DWH statistic cannot be directly applied in a nonlinear framework and plugging in the fitted values from a first stage probit or logit model does not work due to the well known forbidden regression problem. The endogeneity of the NBER dummy variable based on the DWH statistic might be mainly due to the fact that a linear probability model does not provide the best fit for a dummy variable. More importantly, the finding that the industrial production is not endogenous suggests that the realtime recession probabilities $\operatorname{Prob}_{1, t}$ might not suffer as much from an endogeneity problem. 
We now turn our attention to the TSLS estimation of the empirical specification in Equation (7) using the same variables discussed above as instruments..$^{5}$ Table (12) shows that our main results remain unchanged qualitatively when we estimate the effect of unexpected changes in the Fed funds rate on credit spreads over the business cycle while controlling for possible endogeneity of business cycle indicators.

Finally, we focus on the endogeneity of the real-time recession probabilities based only on the growth rate of industrial production. Instead of using the real-time recession probabilities in our empirical specification, we use the one-month ahead forecasts of recession probabilities from the Markov regime switching model. For example, for the probability of recession in May 1989, we first estimate the Markov regime switching model using real-time data available at the end of April 1989. We then form a forecast of the recession probability in May 1989 based on estimated transition and filtered probabilities as in Equation (6). In other words, we use $\operatorname{Prob}_{1, \text { May }}^{f} 1989$ for the recession probability in May 1989. Using forecasts of recession probabilities allows us to eliminate any contemporaneous relation between credit spreads and recession probabilities in our empirical specification since forecasts do not depend on the current business conditions. Although we choose not to present our results based on forecasted recession probabilities for the sake of brevity, they are similar to those based on the contemporaneous probability of recession. In other words, the effect of unexpected changes in the Fed funds rate is positive and significant when the forecasted probability of recession is higher.

\subsection{Control Variables}

One might argue that the significant effect of unexpected changes in the Fed funds rate on credit spreads in recessions might be due to the lack of control variables in our empirical specification. In this section, we analyze the relation between unexpected monetary policy and credit spreads in an empirical specification where we control for other variables that might affect credit spreads. To this extent, we follow Collin-Dufresne et al (2001) and estimate the following empirical specification:

$$
\begin{aligned}
\Delta \text { Spread }_{t} & =\beta_{0}+\beta_{1} U_{t}+\beta_{2} B C I_{t}+\beta_{3}\left(U_{t} \times B C I_{t}\right) \\
& +\beta_{4} \Delta r_{10, t}+\beta_{5}\left(\Delta r_{10, t}\right)^{2}+\beta_{6} \Delta\left(r_{10, t}-r_{2, t}\right) \\
& +\beta_{7} \Delta V I X_{t}+\beta_{8} S P 500_{t}+\varepsilon_{t}
\end{aligned}
$$

where $r_{10, t}$ and $r_{2, t}$ are the yields on the ten and two year treasury bonds, respectively. Monthly yields on government bonds are available to us from the Federal Reserve Bank of St. Louis and they capture the level, slope and curvature of the yield curve. $V I X_{t}$ is a volatility index based on implied volatility from S\&P 500 index options traded on Chicago Board of Option Exchange and captures the market's expectations about future market volatility. $S P 500_{t}$ is the monthly

\footnotetext{
${ }^{5}$ Angrist and Pischke (2009) suggest using the predicted values of a dummy variable from a probit or a logit regression as an instrument in a TSLS framework with an endogenous dummy variable. We estimate a probit or a logit model for the NBER recession dummy variable with the instruments as explanatory variables. We then use the predicted values and its interaction with unexpected changes in the Fed funds rate as instruments in a TSLS estimation of Equation (7). Our results are quite similar to those predicted in the paper and are available from the authors upon request. For consistency with the previous tests, we choose to present the results based on a linear probability model for the NBER dummy variable.
} 
return on the S\&P 500 Index and captures the market's expectations about current and future business conditions. We have all but two of the variables used in Collin-Dufresne et al (2001), change in the firm leverage ratio and slope of the volatility smirk implied by options on S\&P 500 Index futures. We refer the reader to Collin-Dufresne et al (2001) for theoretical motivation for using these variables.

We estimate the empirical specification in Equation (8) via OLS with HAC standard errors for a sample period between February 1990 and December 2008 which is determined by the availability of the VIX index. Table (13) and Table (14) present our empirical results. For sake of brevity, we choose to present results for empirical specifications with one of the ex-post (NBER recession dummy variable) and one of the real-time (recession probabilities based only on industrial production) measures. ${ }^{6}$ First of all, the adjusted $\mathrm{R}^{2} \mathrm{~s}$ of our empirical specifications with control variables are slightly higher than those without control variables, suggesting that the control variables contribute to explaining credit spreads. Secondly, almost all variables have the correct sign predicted by structural models of credit spreads as discussed in Collin-Dufresne et al (2001). The only control variable that has a significant impact on credit spreads is the return on the S\&P 500 index and the negative coefficient estimate confirms our previous findings that credit spreads widen during periods of bad economic climate. More importantly, our results from Section 5.2 remain unchanged and unexpected changes in the Fed funds rate continue to have a significant and positive effect on credit spreads in recessions even when we control for other variables implied by structural models of credit spreads.

Since Collin-Dufresne et al (2001) use S\&P 500 returns as a measure of business conditions, one might argue that S\&P 500 returns and our measures of business conditions capture the same factor in the economy. However, our measures of business conditions continue to have a significant effect on credit spreads even when we include S\&P 500 returns in our empirical specifications. Furthermore, S\&P 500 returns capture on the market's expectation on current and future economic conditions and might also depend on the market participants' sentiments about the economy. On the other hand, our business cycle indicators capture only the current economic conditions and do not possibly depend on market participants' sentiments. Finally although not presented, we also estimate the empirical specification in Equation (7) with monthly returns on the S\&P 500 Index as another business cycle indicator and the results are not significant. These results suggest that our measures of business conditions and S\&P 500 Index returns do not seem to capture the same factor in the economy although these variables might be correlated.

\subsection{Industry-Specific Credit Spreads}

One of the key determinants of credit spreads for individual corporate bonds is the firm leverage ratio. This variable is available for individual firms at a quarterly frequency and one can use a linear interpolation as in Collin-Dufresne et al. (2001) to obtain monthly changes in a firm's leverage ratios to proxy for changes in the firm's health. Although it might not be feasible to

\footnotetext{
${ }^{6}$ Our results based on other measures of business conditions are similar and available from the authors upon request.
} 
calculate a leverage ratio for a bond index, one might still be able to analyze the effect of leverage on the relation between monetary policy and credit spreads by focusing on credit spreads for bonds in different industries with relatively different leverage ratios. To this extent, we obtain monthly yield data on Moody's bond indices for industrial goods and utilities industries with different ratings from the Global Financial Data.

Imperfect capital market theories predict firms with higher leverage ratios to be more adversely affected by unexpected changes in monetary policy since firms with higher leverage ratios tend to have a weaker balance sheet and higher financial distress. In other words, we expect the effect of unexpected changes in the Fed funds rate to be stronger on credit spreads for the industry with a higher leverage ratio. It is still not feasible to calculate the leverage ratio of an industryspecific bond index since the list of firms forming the index is not available to us. Instead, we calculate an weighted average leverage ratio for firms in the S\&P 500 Industrial Goods and Utilities indices where weights are the market value of equity for each firm. Although it might not be a perfect measure and it is not available for a long sample period, the weighted average leverage ratio (the ratio of market value of assets to market value of equity) for the S\&P 500 Industrial Goods and Utilities indices provides some intuition on leverage ratios of the firms in the Moody's industry-specific bond indices. Figure (2) plots the leverage ratios for the S\&P 500 Industrial Goods and Utilities indices between June 2005 and December 2008.

The leverage ratio for utilities has been historically higher than the leverage ratio for industrial goods except for December 2008. Based on this simple leverage ratios, we expect that the effect of unexpected changes in the Fed funds rate to be stronger for credit spreads in the utilities bond index than in the industrial goods bond index. The difference should be even stronger in recessions as predicted by the imperfect capital market theories. To test these implications, we estimate the empirical specification in Equation (8) for industry-specific credit spreads. Tables (15) and (16) present our empirical results for industry-specific credit spreads where the coefficient estimates of the control variables are suppressed for presentation purposes. First of all, our results remain unchanged when we consider industry-specific credit spreads and unexpected changes in the Fed funds rate continue to have a significant effect on credit spreads in recessions. Although the difference is not significant at any conventional level, unexpected changes in the Fed funds rate during recessions have a stronger impact on credit spreads for utility firms than credit spreads for industrial goods firms. The leverage effect is less pronounced when we use the NBER recession dummy variable as a measure of business conditions.

\subsection{An Exponential GARCH Specification for Credit Spreads}

Our summary statistics discussed in Section 4.2 suggest that not only the mean but also the volatility of credit spreads varies with the business cycle with higher volatility in recessions. So far, we focused on the effect of unexpected changes in the Fed funds rate on the level of credit spread changes for several reasons. First of all, the possible endogeneity of business cycle indicators did not allow us to proceed before providing some empirical evidence against the possible endogeneity problem. Secondly, the theory does not provide any clear predictions on the effect of monetary policy on credit spread volatility over the business cycle. Finally, a linear specification without time-varying volatility allowed us to compare our empirical results 
to those in the previous literature. Hence, we decided to use an empirical specification with time-varying volatility as a robustness check rather than as the main empirical specification. To analyze the robustness of our results to time-varying volatility of credit spreads, we estimate the following empirical specification similar to that in Equation (7) where the error term follows an EGARCH specification of Nelson $(1991)^{7}$ :

$$
\begin{aligned}
\Delta \text { Spread }_{t} & =\beta_{0}+\beta_{1} U_{t}+\beta_{2} B C I_{t}+\beta_{3}\left(U_{t} \times B C I_{t}\right)+\varepsilon_{t} \\
\ln \left(\sigma_{t}^{2}\right) & =\gamma_{0}+\gamma_{1} U_{t}+\gamma_{2} B C I_{t}+\gamma_{3}\left(U_{t} \times B C I_{t}\right) \\
& +\gamma_{4} \ln \left(\sigma_{t-1}^{2}\right)+\gamma_{5}\left|\varepsilon_{t-1} / \sigma_{t-1}\right|+\gamma_{6}\left(\varepsilon_{t-1} / \sigma_{t-1}\right)
\end{aligned}
$$

where $\sigma_{t}^{2}$ is the conditional variance of $\varepsilon_{t}$ which is assumed to be normally distributed. ${ }^{8}$ We estimate the empirical specification via maximum likelihood with Bollerslev-Wooldridge robust standard errors. This specification allows to analyze the effect of unexpected changes in the Fed funds rate on both the level and volatility of credit spread changes over the business cycle.

Table (17) presents our empirical results for the credit spread between BAA and AAA rated bonds. ${ }^{9}$ Our main results on the effect of unexpected changes in the Fed funds rate on credit spreads during economic recessions do not change even when we control for time-varying conditional volatility of credit spreads. Credit spreads continue to widen following an unexpected monetary policy tightening during economic recessions. One should always keep in mind that the coefficient estimates on the growth rate of industrial production should have the opposite sign of the coefficient estimates on other business cycle indicators since a lower or negative growth rate of industrial production signifies economic recessions. Several interesting facts about the conditional volatility of credit spreads emerge from the estimation of Equation (9). First of all, lagged conditional volatility and lagged absolute residual have significant coefficient estimates suggesting that conditional volatility of credit spreads are time-varying. Secondly, the conditional volatility of credit spread changes are higher during economic recessions as suggested by the positive and significant coefficient estimate of business cycle indicators in the variance equation except when the business cycle indicator is the growth rate of industrial production. More importantly, the conditional volatility of credit spreads increases following an unexpected monetary policy tightening which might be mainly due to the fact that conditional volatility generally increases following news. This effect becomes negative during economic recessions and the conditional volatility decreases following unexpected monetary policy tightening. The intuition for this negative effect might be as follows: Volatility in financial markets generally depends on the market participants' uncertainty about the state of the economy (e.g. David (1997), Veronesi (1999) and David (2008)). Market participants are generally more uncertain about the state of the economy in recessions (e.g. Veronesi (1999)). Although an unexpected monetary policy tightening might be bad news and increase credit spreads, it might

\footnotetext{
${ }^{7}$ We also estimated a similar specification without any explanatory variables in the conditional variance equation except the EGARCH terms. Our results on the effect of unexpected changes in the Fed funds rate on credit spreads over the business cycle do not change significantly and credit spreads continue to widen following an unexpected monetary policy tightening during economic recessions.

${ }^{8} \mathrm{We}$ also estimated the model assuming that the error term $\left(\varepsilon_{t}\right)$ is distributed with a generalized error distribution. Our results are quite similar to those presented in Table (17) and available from the authors upon request.

${ }^{9}$ For the sake of brevity, we choose to present our results only for the credit spread between BAA and AAA rated bonds. Our results are similar for the two other credit spreads and available from the authors upon request.
} 
also decrease markets participants' uncertainty during economic recessions when it is generally higher.

\section{The Effect of Monetary Policy on Credit Spreads over Credit Cycles}

So far, we have considered the time-varying effect of unexpected changes in the Fed funds rate on credit spreads over the business cycle. Our preliminary analysis in Section 4 suggests that this effect might also change over credit cycles broadly defined as narrowing or widening credit spreads. In this section, we first describe our empirical specification to analyze the time-varying effect of monetary policy on credit spreads over changing credit market conditions. We then discuss our empirical results and the robustness of our results to including control variables in our empirical specification. Finally, we analyze the effect of monetary policy on industryspecific credit spreads.

\subsection{Empirical Results}

To analyze the effect of unexpected changes in monetary policy on credit spreads, we estimate a two state Markov regime switching vector autoregression of Krolzig (1997) for credit spreads for our sample between May 1989 and December 2008. Our empirical specification is motivated by the regime-switching framework of Dionne et al. (2007) where they extend the framework of Bansal and Zhou (2002) to the corporate bond setting. In this setup, macroeconomic factors might have different effects on credit spreads in different states of the world. They find that the inflation rate is an important factor that effects default spreads during their sample period. In a similar setup, Maalaoui et al. (2009) model credit spreads independently from macroeconomic fundamentals as a two-state Markov regime switching model and identify two credit cycles during their sample period. They argue that accounting for these endogenous credit cycles improves the power of structural models to explain credit spreads. Our empirical specification is closest to that of Davies (2004) where he also identifies two distinct regimes in credit spreads in a Markov regime switching framework.

Specifically, we estimate the following model with switching in the mean and the variancecovariance matrix of three credit spreads:

$$
\left(\begin{array}{c}
\Delta(B A A-A A A)_{t} \\
\Delta(B A A-A A)_{t} \\
\Delta(B A A-A)_{t}
\end{array}\right)=\beta_{0, S_{t}}+\beta_{1, S_{t}} U_{t}+\Sigma_{S_{t}}^{1 / 2} \varepsilon_{t}
$$

where $S_{t}$ is the state variable which is assumed to a follow a two state Markov chain; $\beta_{0, S_{t}}, \beta_{1, S_{t}}$ are $3 \times 1$ vectors of coefficients and $\Sigma_{S_{t}}$ is a $3 \times 3$ variance matrix. This specification allows us to identify credit cycles using available information in all three definitions of the credit spreads and without making any ad hoc assumptions about the definition of narrowing and widening spreads.

Table (18) presents the coefficient estimates. The parameter estimates suggest that there are 
two distinct states in credit spreads. The first regime represents periods during which all three credit spreads are narrowing whereas the second regime represents periods during which credit spreads are widening at a relatively faster pace. All three credit spreads have higher volatility in the second state suggesting that credit spreads are more volatile during periods of widening. Not surprisingly, in both states, the credit spread between BAA- and AAA-rated bonds changes with a faster and more volatile pace than the two other credit spreads. The state that represents narrowing credit spreads is more persistent than the state that represents widening credit spreads. This suggests that credit spreads become narrower with a slower pace over long periods whereas they widen with a relatively faster pace over short periods. The figure (3) presents the smoothed probabilities of the state of widening credit spreads along with NBER recession dates.

First of all, there seems to be a strong relation between credit and business cycles. The probability of the state that represents periods of widening credit spreads generally increases to one during economic recessions and decreases to zero during economic expansions. However, there also seem to be periods of widening credit spreads independent of economic recessions. These credit cycles can be related to important events that significantly affected the spreads but not the overall economy. For example, the widening of credit spreads in the early 1990s might be due to the bailout of several savings and loans institutions by the government and the resulting large budget deficit. The widening cycle in 1998 might be due to the effects of the Russian default and the collapse of Long Term Capital Management. The years 2002 and 2003 might be related to large number of defaults following the Telecom burst. The credit cycles are more frequent, less persistent and shorter lived than business cycles.

We now turn our attention to the effect of unexpected changes in the Fed funds rate on credit spreads which seems to be asymmetric over credit cycles. During periods of widening credit spreads, an unexpected monetary policy tightening significantly increases credit spreads and this effect is strongest and most significant for the spread between BAA- and AAA-rated bonds. These results suggest that firms with lower credit ratings are more adversely affected by unexpected changes in the Fed funds rate during bad credit market conditions in line with the predictions of imperfect capital market theories. On the other hand, an unexpected increase in the Fed funds rate decreases credit spreads during periods of narrowing credit spreads. This effect is strongest and most significant for the spread between yields on BAA- and A-rated bonds. This finding is somewhat in contrast with the predictions of imperfect capital market theories as they predict that credit spreads would widen following an unexpected monetary policy tightening during good or bad times. In section 8 , we argue that this inverse relation might be due to the positive effect of an unexpected monetary policy tightening on the market participants' expectations about the future of the economy during good times.

\subsection{Control Variables}

In this section, we analyze the robustness of our results presented in Table (18) to control variables. To this extent, we use the same control variables discussed in Section 5.4 and estimate a two state Markov regime model similar to the one in Equation (10) for the credit spreads where the effect of a variable is allowed to change with the state variable. Specifically, we estimate the 
following specification for the vector of credit spreads between February 1990 and December 2008:

$$
\begin{aligned}
\left(\begin{array}{c}
\Delta(B A A-A A A)_{t} \\
\Delta(B A A-A A)_{t} \\
\Delta(B A A-A)_{t}
\end{array}\right) & =\beta_{0, S_{t}}+\beta_{1, S_{t}} U_{t}+\beta_{2, S_{t}} \Delta r_{10, t} \\
& +\beta_{3, S_{t}}\left(\Delta r_{10, t}\right)^{2}+\beta_{4, S_{t}} \Delta\left(r_{10, t}-r_{2, t}\right) \\
& +\beta_{5, S_{t}} \Delta V I X_{t}+\beta_{6, S_{t}} S P 500_{t}+\Sigma_{S_{t}}^{1 / 2} \varepsilon_{t}
\end{aligned}
$$

where $S_{t}$ is the state variable which is assumed to follow a two state Markov chain; $\beta_{i, S_{t}}$ are $3 \times 1$ vectors of coefficients and $\Sigma_{S_{t}}$ is a $3 \times 3$ variance matrix. Our results from the previous section continue to hold even when we control for other variables that might have an effect on credit spreads. Several interesting facts about the effect of control variables on credit spreads emerge from our results. First of all, variables that do not have a significant effect on credit spreads when we do not distinguish between different states tend to have a significant effect either during periods of widening or narrowing credit spreads. For example, a change in 10year government bond yield does not have a significant effect on credit spreads between BAA and AAA rated bonds when we do not distinguish different cycles in credit spreads. However, it has a negative significant effect during periods of narrowing credit spreads and a positive significant effect during periods of widening credit spreads. The negative significant impact of S\&P 500 returns on credit spreads is generally during periods of narrowing spreads and it becomes insignificant during periods of widening credit spreads.

\subsection{Industry-Specific Credit Spreads}

In this section, we analyze the effect of unexpected changes in the Fed funds rate on industryspecific credit spreads over the credit cycles. To this extent, we estimate the Markov regime switching model in Equation (10) for credit spreads in industrial goods and utilities bond indices between May 1989 and December 2008. Based on imperfect capital market theories, one would expect credit spreads in the utilities bond index to be more adversely affected by unexpected changes in the Fed funds rate than credit spreads in the industrial goods bond index since firms in the utilities industry generally have a higher leverage ratio. This effect should also be more pronounced during periods of deteriorating credit market conditions which generally correspond to periods of widening credit spreads. Tables (20) and (21) present our empirical results for the industrial goods and utilities bond indices, respectively. Unexpected changes in the Fed funds rate do not have a significant effect on credit spreads in the industrial goods bond indices. On the other hand, credit spreads in the utilities bond indices increase significantly following an unexpected increase in the Fed funds rate during periods of widening credit spreads. When we include control variables in our empirical specification as in Equation (11), our results do not change qualitatively and unexpected changes in the Fed funds rate continue to have a significant effect on credit spreads in the utilities bond indices during periods of widening credit spreads. These results suggest that firms with higher leverage ratios are more adversely affected by changes in monetary policy especially during bad credit market conditions. 


\section{The Effect of Monetary Policy on Credit Spreads over the Monetary Policy Cycle}

In this section, we analyze the effect of unexpected changes in the Fed funds rate on credit spreads over the monetary policy cycle. We first discuss our measures of monetary policy cycles which include but are not limited to those discussed in Section 4.2. We then present our empirical results based on an empirical specification similar to that discussed in Section 5.3. Finally, as in previous sections, we discuss the robustness of our results.

\subsection{Monetary Policy Cycle Indicators}

We define the monetary policy cycle based on either the actual or expected change in the Fed funds rate in a given month. If the actual change in the Fed funds rate in a given month is positive (negative), then we consider this period to be a period of contractionary (expansionary) monetary policy. Similarly, if the actual change is zero, then it is considered to be a period of neutral monetary policy. The monetary policy cycle based on the expected change in the Fed funds rate is defined similarly. In this framework, if the Fed decides to keep the rate at its current level in a given month, we consider this month to be a period of neutral monetary policy. However, in reality, the Fed might be just waiting between two consecutive expansionary or contractionary monetary policy periods. For example, in April 2000, the Fed decided to keep the rate at its level at the end of March after two consecutive increases of 25 basis points in February and March. They further increased the rate by another 50 basis points in May. Our indicator of monetary policy based on the actual change in the Fed funds rate assumes that April 2000 is a period of neutral monetary policy. In reality, it was a break period for the Fed between two consecutive increases in the Fed funds rate. To this extent, we also define two other dummy variables for periods of expansionary monetary policy based on either the actual or the expected change in the Fed funds rate. The dummy variable takes the value one (a) if the current actual (or expected) change is negative or (b) if the actual (expected) change is zero and the last non-zero actual (expected) change were negative. Otherwise, the dummy variable takes the value zero. This variable is similar to the reversal dummy variable used in Bernanke and Kuttner (2005) to capture reversals in monetary policy.

Table (22) presents the correlation between four measures of expansionary monetary policy, the NBER recession dummy variable and real-time recession probabilities. Although measures of expansionary monetary policy are positively correlated, they are not perfectly related. Furthermore, as expected, measures of expansionary monetary policy are positively correlated with recessions, suggesting that the Fed follows (and is expected to follow) an expansionary monetary policy during periods of economic slowdown.

\subsection{Empirical Results}

To analyze the effect of unexpected changes in the Fed funds rate on credit spreads over the monetary policy cycle, we estimate an empirical specification similar to Equation (7) where we replace the business cycle indicator with one of the four indicators of expansionary monetary policy. Specifically, we estimate the following empirical specification via OLS with HAC 
standard errors:

$$
\Delta \text { Spread }_{t}=\beta_{0}+\beta_{1} U_{t}+\beta_{2} M P C I_{t}+\beta_{3}\left(U_{t} \times M P C I_{t}\right)+\varepsilon_{t}
$$

where $M P C I_{t}$ is monetary policy cycle indicator that takes the value one if the monetary policy is expansionary and zero otherwise. The interaction term allows us to analyze the marginal effect of unexpected changes in the Fed funds rate on credit spreads during periods of expansionary monetary policy. We expect the coefficient estimate of the interaction term to be positive and significant since the Fed generally follows an expansionary monetary policy during periods of economic slowdown when the effect of an unexpected change in the Fed funds rate would be more pronounced.

Table (23) presents our empirical results. First of all, credit spreads generally widen during periods of expansionary monetary policy. To understand this result, one needs to take into account the fact that periods of expansionary monetary policy generally correspond to periods of economic slowdown. Secondly, unexpected changes in the Fed funds rate do not have a significant effect on credit spreads when we do not distinguish between different monetary policy cycles. On the other hand, the effect becomes positive and significant during periods of expansionary monetary policy although the significance changes across credit spreads and definitions of expansionary monetary policy. These results suggest that credit spreads widen following an unexpected monetary policy tightening during periods of expansionary monetary policy. The intuition behind these results follows from the relation between monetary policy and business conditions. As discussed above, the Fed generally follows (and is expected to follow) an expansionary monetary policy during periods of economic slowdown. Hence, in line with the predictions of capital market theories, credit spreads generally widen following an unexpected monetary policy tightening during periods of economic slowdown and expansionary monetary policy.

As discussed in Sections 4.1 and 4.3, the actual and expected changes might suffer from an endogeneity problem. Given the relatively weak evidence on the effect of unexpected changes in the Fed funds rate over the monetary policy cycle, we choose not to discuss the possible endogeneity of monetary policy cycle indicators. We believe that the actual changes might suffer more from a possible endogeneity problem than expected changes, which might explain the significant relation between credit spreads and the monetary policy cycle indicator based on actual changes.

\subsection{Control Variables}

We now turn our attention to the robustness of our results to control variables. To this extent, we estimate the empirical specification in Equation (12) with the control variables discussed in Section 5.5. Although not presented for the sake of brevity, we briefly discuss the results. First of all, the only control variable that seems to have a marginally significant effect on credit spreads in the empirical specification is the square change in the 10 year bond yield. More importantly, the effect of unexpected changes in the Fed funds rate on the credit spread between BAA- and AAA-rated bonds continues to be positive and significant during periods of expansionary monetary policy even when we control for other variables that might affect credit 
spreads. The effect during periods of expansionary monetary policy also becomes significant for credit spreads between BAA- and AA- and A-rated bonds for most definitions of expansionary monetary policy.

\subsection{Industry-Specific Credit Spreads}

Here, we analyze the effect of unexpected changes in the Fed funds rate on industry-specific credit spreads over the monetary policy cycle. As discussed in Section 5.6, one of the most important determinants of credit spreads is the leverage ratio which is not available to us for bond indices. As before, to analyze the effect of leverage on the relation between monetary policy and credit spreads, we focus on credit spreads in industries with different leverage ratios. To this extent, we estimate the empirical specification in Equation (12) with control variables for industry-specific credit spreads. Since utilities firms generally have higher leverage ratios than industrial goods firms, we expect credit spreads between firms in the utilities industry to be more sensitive to unexpected changes in the Fed funds rate and this effect to be more pronounced during periods of expansionary monetary policy.

Although not presented, the effect of unexpected changes in the Fed funds rate on industryspecific credit spreads over the monetary policy cycle is similar to the results for overall corporate credit spreads. Industry-specific credit spreads tend to widen following an unexpected monetary policy tightening during periods of expansionary monetary policy. As before, the effect of unexpected monetary policy tightening is more pronounced for credit spreads in the industry with a higher leverage ratio (utilities) than those in the industry with a lower leverage ratio (industrial goods).

\section{Further Robustness Checks}

In this section, we briefly discuss the results of few additional robustness tests although we choose not to present these results for the sake of brevity.

(a) Delayed Effect

To control for any delayed effect, we include lagged unexpected changes in the Fed funds rate in empirical specifications in Equations (7), (10) and (12). The significance of our results on the effect of monetary policy during bad times does not change independent of indicators used. Furthermore, unexpected changes in the Fed funds rate do not seem to have any significant effect on credit spreads over the business, credit or monetary policy cycles.

(b) Nonlinear Effect

To control for any further nonlinear effect of monetary policy on credit spreads, we include the squared unexpected changes in the Fed funds rate in empirical specifications in Equations (7), (10) and (12). The significance of our results on the effect of monetary policy during bad times does not change independent of indicators used. For some definitions of credit spreads, the squared unexpected change in the Fed funds rate has a positive and significant effect on credit 
spreads during bad times over the business, credit and monetary policy cycles. This result suggests that monetary policy might have a further nonlinear effect on credit spreads that is not further analyzed in this paper.

(c) Delayed Nonlinear Effect

We include the lagged squared unexpected change in the Fed funds rate as an additional control variable in empirical specifications in Equations (7), (10) and (12). Our results on the effect of monetary policy on credit spreads during bad times continue to hold and there seems to be no significant delayed nonlinear effect of monetary policy on credit spreads.

(d) Subsample Stability and Outliers

Our results from Part (b) of this section suggest that unexpected changes in the Fed funds rate might have a nonlinear effect on credit spreads. This in turn might signal an impact of outliers on empirical results. Furthermore, the Fed changed its policy and started announcing the target rate changes in February 1994. Before then, the market participants inferred about the Fed's decisions through the open market operations. Hence, to analyze the robustness of our results to outliers and subsamples, we estimate the empirical specifications by removing observations before February 1994 to remove the effect of the change in the Fed's policy, observations after December 2006 to remove the effect of the recent financial events and the observation on September 2001 to remove the effect of the September 11. We define an observation to be an outlier if it is three standard deviations away from the sample mean of unexpected changes in the Fed funds rate. According to these definitions, there is a total of seven outliers in our whole sample, five outliers before February 1994, one after December 2006 and one (on January 2001) in our subsample between February 1994 and December 2006. Our main results on the timevarying effect of unexpected changes in the Fed funds rate remain unchanged when we estimate the empirical specifications using the described subsample.

\section{The Effect of Monetary Policy on Credit Spreads in a Joint Framework}

So far, we have analyzed the effect of monetary policy on credit spreads over different macroeconomic cycles separately. These separate analysis allow us to identify the effect of changing conditions in different macroeconomic factors on the relation between monetary policy and credit spreads. An alternative approach would be to analyze the effect of monetary policy on credit spreads in a joint framework since the different cycles in the economy are related and jointly determined by other macroeconomic factors. In this section, we analyze the effect of monetary policy on credit spreads in a framework where we do not necessarily distinguish between different cycles in the economy but rather allow the state to be jointly determined by business and credit market conditions as well as monetary policy. To this extent, we estimate a Markov regime switching model similar to Equation (10) for the growth rate of industrial production, credit spreads and actual changes in the Fed funds rate. The intuition behind this empirical specification is simple. In this framework, the latent state variable cannot be interpreted as business, credit or monetary policy cycles as it is jointly determined by changing conditions in 
all these three macroeconomic factors. Specifically, we estimate the following Markov regime switching model for three credit spreads, the growth rate of industrial production and actual changes in the Fed funds rate where both the mean vector and the variance-covariance matrix depend on the latent state variable:

$$
\left(\begin{array}{c}
\Delta(B A A-A A A)_{t} \\
\Delta(B A A-A A)_{t} \\
\Delta(B A A-A)_{t} \\
\Delta \ln \left(I P_{t}\right) \\
A_{t}
\end{array}\right)=\beta_{0, S_{t}}+\beta_{1, S_{t}} U_{t}+\Sigma_{S_{t}} \varepsilon_{t}
$$

where $S_{t}$ is the state variable which is assumed to follow a two state Markov chain; $\beta_{i, S_{t}}$ are $5 \times 1$ vectors of coefficients and $\Sigma_{S_{t}}$ is a $5 \times 5$ diagonal variance matrix. ${ }^{10}$

Table (24) presents our empirical results. First of all, there are again two distinct states one with narrowing credit spreads, growing industrial production and contractionary monetary policy and one with widening credit spreads, decreasing industrial production and expansionary monetary policy. The first state can be considered to represent good times in the economy when all three macroeconomic factors (credit spreads, industrial production and monetary policy) indicate improving business and credit conditions. The second state can be similarly considered to represent bad times with deteriorating economic conditions. All three macroeconomic factors also have higher volatilities during bad times than good times suggesting that the economy overall becomes more volatile during bad times. Turning our attention to the effect of monetary policy on credit spreads, our results are similar to those discussed above. In line with the predictions of imperfect capital market theories, unexpected changes in the Fed funds rate have a positive and significant effect on credit spreads during bad times suggesting that credit spreads widen following an unexpected monetary policy tightening during bad times. The effect is strongest for the credit spread between BAA- and AAA-rated bonds. On the other hand, similarly to our previous results, the effect becomes negative and significant during good times. This effect is strongest for the credit spread between BAA- and A-rated bonds. As discussed above, this effect is somewhat in contrast with the predictions of imperfect capital markets since our results suggest that credit spreads narrow following an unexpected monetary policy tightening during good times. In the following section, we argue that this might be mainly due to the time-varying effect of unexpected changes in the Fed funds rate on the market participants' expectations during good and bad times.

Our results based on this joint framework can also be considered as further empirical evidence for the robustness of the effect of monetary policy on credit spreads over the business cycle. This framework allows us to analyze the effect of monetary policy on credit spreads during good and bad times without the possibility of an endogeneity problem unlike the business cycle indicators. Although the state variable cannot be considered as an indicator of the business cycle in this framework, it is still correlated with the business cycle as it is partially determined by

\footnotetext{
${ }^{10}$ Differently from the Markov regime switching model in Equation (10) where we estimate a full variancecovariance matrix with non-diagonal elements, here we assume that the variance-covariance matrix is diagonal. The diagonality assumption is force upon us mainly due to the large number of parameters that need to be estimation in a full variance covariance matrix which causes some convergence problems.
} 
the growth rate of industrial production. Our results in this section confirm that the effect over the business cycle is not possibly due to the endogeneity of our business cycle indicators.

\section{Discussion}

Our results suggest that credit spreads widen following an unexpected increase in the Fed funds rate during bad times in line with the predictions of imperfect capital market theories. On the other hand, we find that the effect of monetary policy on credit spreads changes sign and credit spreads narrow following an unexpected monetary policy tightening during good times. It is relatively harder to justify this inverse relationship with imperfect capital market theories which predict that credit spreads would widen following an unexpected monetary policy tightening independent of macroeconomic conditions. In this section, we provide a possible explanation for this observed empirical phenomenon based on results discussed in Romer and Romer (2000). We do not necessarily argue that our explanation is the only possible one but rather provide some empirical evidence on this possible explanation.

We argue that this inverse relation during good times might be mainly due to the positive effect of an unexpected monetary policy tightening on the market participants' expectations about the future of the economy during good times. Our argument can be summarized as follows: Assuming that changes in the Fed funds rate partially reveal the Fed's expectations about the future of the economy, market participants update their expectations about the future of the economy in face of additional information. During good times, an unexpected increase in the Fed funds rate might reveal that the Fed expects the economy to grow faster than they previously thought. In other words, an unexpected increase in the Fed funds rate might be considered as good news about improving economic conditions during good times. Since credit spreads generally narrow following good economic news, they also narrow following an unexpected increase in the Fed funds rate during good times. In this section, we first discuss the empirical framework to analyze the effect of monetary policy on the market participants' expectations. We then present and discuss our empirical results for the effect of monetary policy on inflation expectations during good times and bad times.

The motivation behind our argument is based on Romer and Romer (2000) where they show that the Federal Reserve has additional information above and beyond what is known to commercial forecasters. The Federal Reserve partially reveals this additional information through its policy actions. Using changes in the Fed funds rate as one of the indicators of Federal Reserve actions, they show that commercial forecasters raise their expectations of inflation, and hence their expectations about future economic growth, following a monetary policy tightening in contrast to the predictions of more conventional monetary policy models. ${ }^{11}$ In this section, we take their argument one step further and argue that an unexpected monetary policy tightening increases the market participants' expectations about the future of the economy during good times but not during bad times. To test this hypothesis, we estimate the following empirical specification via

\footnotetext{
${ }^{11}$ Romer and Romer (2000), Amato et al. (2002), Ellingsen and Soderstrom (2004), Beechey (2007) and Chun (2005) discuss the importance of market participants' expectations in analyzing the effect of monetary policy on interest rates.
} 
OLS with HAC standard errors:

$$
\pi_{t}=\alpha_{0}+\alpha_{1} \pi_{t-1}+\alpha_{2} U_{t}+\alpha_{3}\left(1-\operatorname{Prob}_{t}\right)+\alpha_{4} U_{t}\left(1-\operatorname{Prob}_{t}\right)+\nu_{t}
$$

where $\pi_{t}$ represents the market participants' expectations about the future of the economy in month $t$. In this empirical specification, any real-time measure of economic conditions can be included to control for the time-varying effect of monetary policy on market participants' expectations. It is important to use a real-time measure that only depends on the market participants' information set when they form their expectations. We choose to use the real-time probability of expansions based only on the growth rate of industrial production, $1-$ Prob $_{t}$. To capture the market participants' expectations about the future of the economy, we use the only two monthly survey expectations available to us: The Conference Board Inflation Expectations and University of Michigan Inflation Expectations. ${ }^{12}$

Our empirical specification is similar to that in Romer and Romer (2000) but differs in several ways. First of all, we employ unexpected changes in the Fed funds rate rather than actual changes. Secondly, we include a real-time measure of changing economic conditions to capture the state-dependent effect of monetary policy on market participants' expectations. Finally, we do not control for changes in the Fed's own inflation forecasts due to the fact that the Fed's Greenbook forecasts are not available for the whole period of our sample. Romer and Romer (2000) include the change in the Fed's inflation forecasts to control for general information that becomes available between two forecast periods. We believe that this is not as important of a problem in our analysis since we use unexpected changes in the Fed funds rate rather than actual changes. Any additional information that becomes available should be captured in the expected change in the Fed funds rate.

Table (25) presents our empirical results. First of all, lagged values of inflation expectations are significant and capture most of the variation in current inflation expectations. Secondly, inflation expectations are higher during periods of economic growth when the probability of expansion is high. More importantly, the overall effect of an unexpected monetary policy tightening is to decrease the market participants' expectations about future inflation, and hence about future economic conditions, as suggested by the negative and significant coefficient estimate on $U_{t}$. However, this effect changes sign and becomes positive during periods of economic growth when the probability of recession is high, suggesting that market participants become more optimistic about the future of the economy following an unexpected monetary policy tightening in expansions. These results suggest that market participants might interpret an unexpected increase in the Fed funds rate during good times as good news about the future economic conditions. Since credit spreads generally narrow following good news about the future of the economy, this positive effect might explain why credit spreads narrow following an unexpected monetary policy tightening during good times.

\footnotetext{
${ }^{12}$ Other alternative measures of the market participants' expectations about the future of the economy are the Blue Chip, Data Resources Inc. and Survey of Professional Forecasters. The first two were not available to us and the third is only available at a quarterly frequency rather than a monthly frequency.
} 


\section{Conclusion}

In this paper, we analyze the effect of monetary policy on credit spreads. Specifically, we analyze how unexpected changes in the Fed funds rate affects changes in yield spreads between corporate bonds of firms with different credit ratings. We use the Fed funds futures to distinguish between expected and unexpected changes in the Fed funds rate. We find that unexpected changes in the Fed funds rate does not have a significant effect on credit spreads when we do not distinguish between different periods. However, credit spreads significantly increase (decrease) following an unexpected monetary policy tightening (easing) during periods of economic slowdown, widening credit spreads or expansionary monetary policy. These results are in line with the predictions of imperfect capital market theories which argue that firms with lower credit ratings would be more sensitive to unexpected changes in monetary policy than firms with high credit ratings. These models also predict that this effect would be more pronounced during periods of deteriorating market conditions. We also find that credit spreads narrow (widen) following an unexpected monetary policy tightening (easing) during periods of improving economic and credit market conditions. We argue that this inverse relation between monetary policy and credit spreads during good times might be mainly due to the fact that market participants raise their expectations about the future of the economy following an unexpected monetary policy tightening during good times but not during bad times. 


\section{References}

[1] Amato, J. D., Morris, S., and Shin, H. S., (2002) "Communication and Monetary Policy.", Oxford Review of Economic Policy, 18, 495-503.

[2] Andersen, T. G., Bollerslev, T., Diebold, F. X., and Vega, C., (2007) "Real-time Price Discovery in Global Stock, Bond and Foreign Exchange Markets.", Journal of International Economics, 73, 251-277.

[3] Angrist, J. D., and Pischke, J., (2009) "Mostly Harmless Econometrics: An Empiricist's Companion.”, Princeton University Press.

[4] Avramov, D., Gergana, J., and Alexander, P., (2007) "Understanding Changes in Corporate Credit Spreads.”, Financial Analysts Journal, 63, 90-105.

[5] Bansal, R., and Zhou, H., (2002) “Term Structure of Interest Rates with Regime Shifts.", Journal of Finance, 5, 1997-2043.

[6] Beckworth, D., Moon, K. P., and Toles, J. H., (2009) "Monetary Policy and Corporate Bond Yield Spreads.”, Applied Economics Letters, 1466-4291.

[7] Beechey, M., (2007) "A Closer Look at the Sensitivity Puzzle: The Sensitivity of Expected Future Short Rates and Term Premia to Macroeconomic News.", Finance and Economic Discussion Series, Board of Governors of the Federal Reserve.

[8] Bernanke, B. S., and Blinder, A. S., (1988) “Credit, Money, and Aggregate Demand.", American Economic Review, 78, 435-439.

[9] Bernanke, B. S., and Blinder, A. S., (1992) "The Federal Funds Rate and the Channels of Monetary Transmission.”, American Economic Review, 82, 901-921.

[10] Bernanke, B. S., and Gertler, M., (1989) "Agency Costs, Net Worth, and Business Fluctuations.", American Economic Review, 79, 14-31.

[11] Bernanke, B. S., and Kuttner, K.N., (2005) "What Explains the Stock Market's Reaction to Federal Reserve Policy?", Journal of Finance, 60, 1221-1257.

[12] Berument, H., and Froyen, R., (2006) "Monetary Policy and Long-term US Interest Rates.", Journal of Macroeconomics, 28, 737-751.

[13] Bevan, A., and Garzarelli, F., (2000) "Corporate Bond Spreads and the Business Cycle.", Journal of Fixed Income, 9, 8-18.

[14] Cenesizoglu, T., (2008) "Size, Book-to-Market Ratio and Macroeconomic News.", Working Paper, HEC Montreal.

[15] Chauvet, M., and Piger, J., (2008) "A Comparison of the Real-Time Performance of Business Cycle Dating Methods.", Journal of Business and Economic Statistics, 26, 42-49. 
[16] Chun, A. L., (2005) "Expectations, Bond Yields and Monetary Policy.”, Working Paper, Copenhagen Business School.

[17] Cochrane, J. H., (2002) "Stocks as Money: Convenience Yield and the Tech-Stock Bubble.”, NBER Working Paper, No. 8987.

[18] Collin-Dufresne, P., Goldstein, R. S., and Martin, J. S., (2001) "The Determinants of Credit Spread Changes.", Journal of Finance, 56, 2177-2208.

[19] Cook, T., and Hahn T., (1989) "The Effect of Changes in the Federal Funds Rate Target on Market Interest Rates in the 1970s.", Journal of Monetary Economics, 24, 331-351.

[20] Curdia, V., and Woodford, M., (2009) "Credit Spreads and Monetary Policy.", NBER Working Paper, No. 15289.

[21] David, A., (1997) "Fluctuating Confidence in Stock Markets: Implications for Returns and Volatility.", Journal of Financial and Quantitative Analysis ,427-462.

[22] David, A., (2008) "Inflation Uncertainty, Asset Valuations, and the Credit Spreads Puzzle.", Review of Financial Studies, 1-48.

[23] Davidson, R., and MacKinnon, J. G., (1993) “Estimation and Inference in Econometrics.", Oxford University Press.

[24] Davies, A., (2004) “Credit Spread Modeling with Regime Switching Techniques.”, Journal of Fixed Income, 14, 36-48.

[25] Davies, A., (2008) “Credit Spread Determinants: An 85 Year Perspective.", Journal of Financial Markets, 11, 180-197.

[26] Demiralp, S., and Jorda, O., (2004) "The Response of Term Rates to Fed Announcements.", Journal of Money, Credit, and Banking, 36, 387-406.

[27] Dionne, G., Gauthier, G., Hammami, K., Maurice, M., and Simonato, J. G., (2007) "A Reduced Form Model of Default Spreads with Markov Switching Macroeconomic Factors.", Working Paper, Canada Research Chair in Risk Management.

[28] Durbin, J., (1954) “Errors in Variables.", Review of the International Statistical Institute, $22,23-32$.

[29] Ellingsen, T., and Soderstrom, V., (2004) "Why are long rates sensitive to monetary policy.”, Working Paper, Stockholm School of Economics.

[30] Fama, E. F., and French, K., (1989) "Business Conditions and Expected Returns on Stocks and Bonds.", Journal of Financial Economics, 25, 23-49.

[31] Faust, J., Rogers, J.H., Wang, S. B. and Wright, J.H., (2007) “The High-Frequency Response of Exchange Rates and Interest Rates to Macroeconomic Announcements.", Journal of Monetary Economics, 54, 1051-1068. 
[32] Gertler, M., and Gilchrist, S., (1994) "Monetary Policy, Business Cycles, and the Behaviour of Small Manufacturing Firms.", Quarterly Journal of Economics, 109, 309-340.

[33] Gurkaynak, R. S., Sack, B., and Swanson, E., (2005) "The Sensitivity of Long-term Interest Rates to Economic News: Evidence and Implications for Macroeconomic Models.", American Economic Review, 95, 425-436.

[34] Gurkaynak, R. S., Sack, B., and Swanson, E., (2007) "Market-Based Measures of Monetary Policy Expectations.", Journal of Business and Economic Statistics, 25, 201-12.

[35] Hausman, J. A., (1978) "Specification Tests in Econometrics.", Econometrica, 46, 12511271.

[36] Kashyap, A. K., Stein, J. C., and Wilcox, D. W., (1993) "Monetary Policy and Credit Conditions: Evidence from the Composition of External Finance.", American Economic Review, 86, 79-98.

[37] Kiyotaki, N., and Moore, J., (1997) “Credit Cycles.”, Journal of Political Economy, 105, 211-248.

[38] Kim , J., Ni, S., and Ratti, R. A., (1998) "Monetary Policy and Asymmetric Response in Default Risk.", Economics Letters, 60, 83-90.

[39] Krolzig, H. M., (1997) "Markov-Switching Vector Autoregressions. Modelling, Statistical Inference and Application to Business Cycle Analysis.", Lecture Notes in Economics and Mathematical Systems, Volume 454, Berlin: Springer

[40] Kuttner, K. N., (2001) "Monetary Policy Surprises and Interest Rates: Evidence from the Fed Funds Futures Market.", Journal of Monetary Economics, 47, 523-544.

[41] Maalaoui, O., Dionne, G., and Francois, P., (2009) "Detecting Regime Shifts in Corporate Credit Spreads.", Working Paper.

[42] McCulley, P., and Toloui, M., (2008) "Chasing the Neutral Rate Down: Financial Conditions, Monetary Policy, and the Taylor Rule.”, Global Central Bank Focus, PIMCO, February 20 .

[43] Mishkin, F. S., (2008) "Monetary Policy Flexibility, Risk Management and Financial Disruptions.", Speech delivered on January 11.

[44] Nelson, D. B., (1991) "Conditional Heteroskedasticity in Asset Returns: A New Approach.”, Econometrica, 59, 347-370.

[45] Poole, W., Rashe, R. H., and Thornton, D. L., (2002) "Market Anticipations of Monetary Policy Actions.", Federal Reserve Bank of St. Louis Review, 84, 75-79.

[46] Rigobon, R., and Sack, B., (2004) “The Impact of Monetary Policy on Asset Prices.", Journal of Monetary Economics, 51, 1553-1575. 
[47] Romer, C., and Romer, D., (2000) "Federal Reserve Information and the Behavior of Interest Rates.", American Economic Review, 90, 429-457.

[48] Staiger, D., and Stock, J.H., (1997) "Instrumental Variables Regression with Weak Instruments.", Econometrica, 65, 557-586.

[49] Stock, J. H., and Yogo., M., (2005) “Testing for Weak Instruments in Linear IV Regression.”, In Identification and Inference for Econometric Models: Essays in Honor of Thomas Rothenberg, Cambridge University Press, 80-108.

[50] Taylor, J. B., (1993) "Discretion versus Policy Rules in Practice.", Carnegie- Rochester Conference Series on Public Policy, 39, 195-214.

[51] Taylor, J. B., (2008) "Monetary Policy and the State of the Economy.", Testimony before the Committee on Financial Services, U.S. House of Representatives, February 26.

[52] Veronesi, P., (1999) "Stock Market Overreaction to Bad News in Good Times: A Rational Exceptions Equilibrium Model.”, Review of Financial Studies, 975-1007.

[53] Wu, D. M., (1974) “Alternative Tests of Independence between Stochastic Regressors and disturbances: Finite sample results.", Econometrica, 42, 529-546. 
Figure 1: Business Cycle Indicators

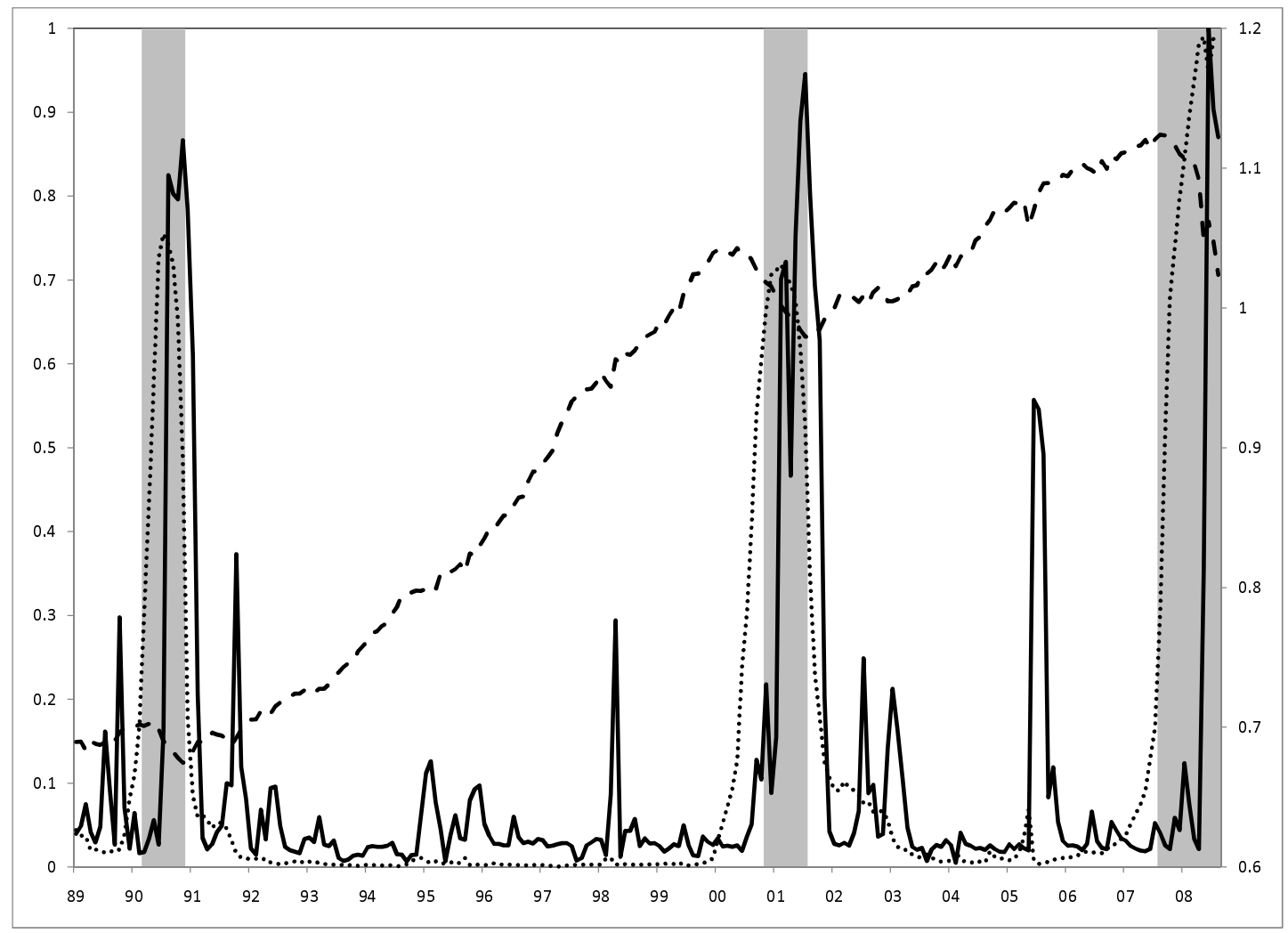

Notes: This figure plots the time-series of real-time recession probabilities $\left(\operatorname{Prob}_{1, t}\right.$ and $\left.\operatorname{Prob}_{2, t}\right)$, the industrial production index $\left(I P_{t}\right)$ and NBER recession periods $\left(N B E R_{t}\right)$ between May 1989 and December 2008. The solid line represents the real-time recession probability based on a two-state Markov regime switching model for the real-time growth rate of the industrial production index $\left(\operatorname{Prob}_{1, t}\right)$. The dotted line represents the real-time recession probability from Chauvet and Piger (2008) available at http://www.uoregon.edu/ jpiger/us_recession_probs.htm $\left(\operatorname{Prob}_{2, t}\right)$. The dashed line represents the industrial production index $\left(I P_{t}\right)$ divided by 100 and is measured on the right axis. The shaded regions are the NBER recessions $\left(N B E R_{t}\right)$. 
Figure 2: Leverage Ratios for S\&P 500 Industrial Goods and Utilities Indices

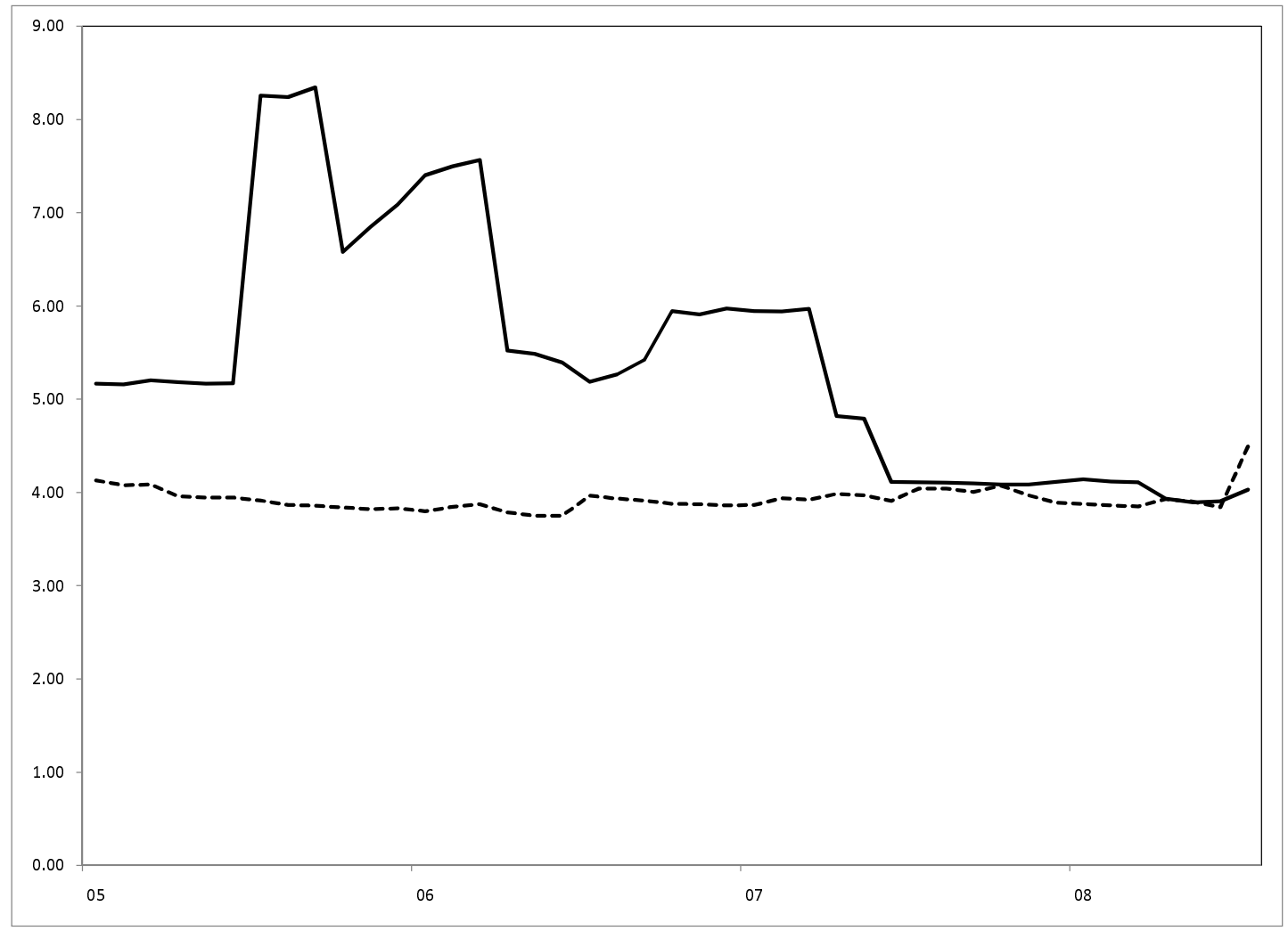

Notes: This figure plots leverage ratios for the S\&P 500 Industrial Goods and Utilities indices between June 2005 and December 2008. The leverage ratio is the weighted average leverage ratio (the ratio of market value of assets to market value of equity) of firms in an index where the weights are determined by market value of equity of each firm forming the index. The solid and dashed lines represent the leverage ratio for the S\&P 500 Industrial Goods and Utilities indices, respectively. 
Figure 3: Credit Cycles (Smoothed Probability of Widening Credit Spreads State)

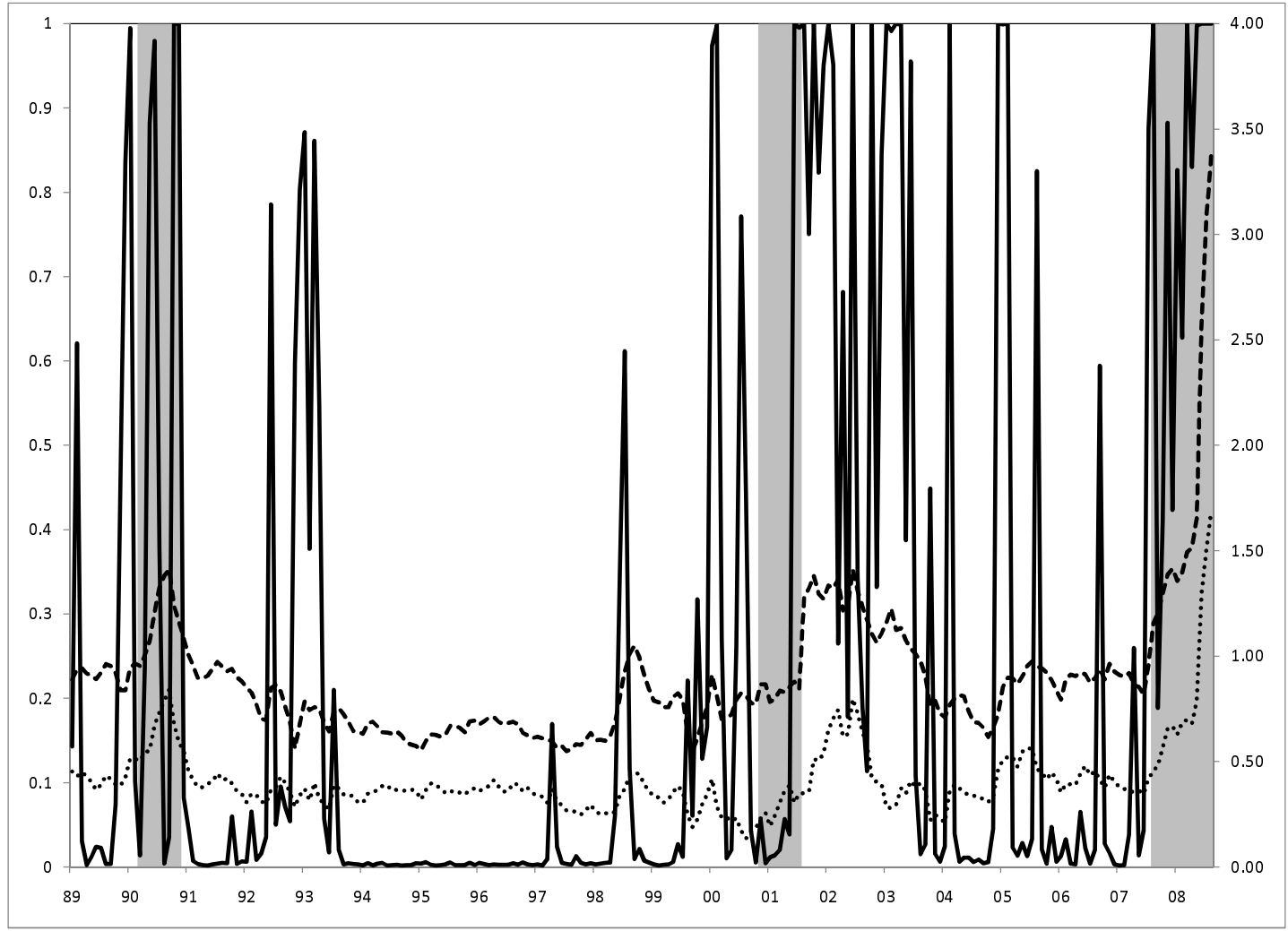

Notes: This figure plots the smoothed probability of the state that represents periods of widening credit spreads as well as BAA-AAA and BAA-A credit spreads between May 1989 and December 2008. The solid line represents the smoothed probability of the state that represents periods of widening credit spreads. The dashed and dotted lines are BAA-AAA and BAA-A credit spreads, respectively. The shaded regions are the NBER recessions. 
Table 1: The Effect of Unexpected Changes in the Fed Funds Rate on Credit Spreads

$$
\Delta \text { Spread }_{t}=\beta_{0}+\beta_{1} U_{t}+\varepsilon_{t}
$$

\begin{tabular}{lccc}
\hline \hline Variable & $\Delta(B A A-A A A)$ & $\Delta(B A A-A A)$ & $\Delta(B A A-A)$ \\
\hline Constant & 1.4238 & 1.0447 & 0.6293 \\
$U_{t}$ & 0.1024 & 0.0695 & 0.0253 \\
& & & \\
\hline Adjusted- $R^{2}$ & $0.7340 \%$ & $0.3229 \%$ & $-0.2586 \%$ \\
\hline \hline
\end{tabular}

Note: This table presents the effect of unexpected $\left(U_{t}\right)$ changes in the Fed funds rate on changes in credit spreads. The coefficient estimates are based on an OLS estimation with HAC standard errors. *** denotes significance at $1 \%$ confidence level, $* *$ denotes significance at $5 \%$ confidence level, * denotes significance at $10 \%$ confidence level. 
Table 2: Summary Statistics over the Business Cycle

Unexpected Change $\left(U_{t}\right)$

\begin{tabular}{lccc}
\hline \hline & Recession & Expansion & Whole sample \\
\hline Mean & -5.9615 & -2.9017 & -3.3037 \\
Std. Dev. & 17.8224 & 8.2795 & 10.0563 \\
Correlation & 1.0000 & 1.0000 & 1.0000 \\
Obs. & 31 & 205 & 236 \\
\hline \hline
\end{tabular}

$$
\triangle(B A A-A A A)
$$

\begin{tabular}{lccc}
\hline \hline & Recession & Expansion & Whole sample \\
\hline Mean & 8.6939 & -0.0652 & 1.0854 \\
Std. Dev. & 19.7053 & 6.2058 & 9.5809 \\
Correlation & 0.2717 & 0.0280 & 0.1075 \\
Obs. & 31 & 205 & 236 \\
\hline \hline
\end{tabular}

$$
\triangle(B A A-A A)
$$

\begin{tabular}{lccc}
\hline \hline & Recession & Expansion & Whole sample \\
\hline Mean & 7.7542 & -0.2341 & 0.8125 \\
Std. Dev. & 16.1685 & 5.3287 & 8.0830 \\
Correlation & 0.2586 & 0.0081 & 0.0864 \\
Obs. & 31 & 205 & 236 \\
\hline \hline
\end{tabular}

$$
\triangle(B A A-A)
$$

\begin{tabular}{lccc}
\hline \hline & Recession & Expansion & Whole sample \\
\hline Mean & 4.8834 & -0.1112 & 0.5456 \\
Std. Dev. & 11.2997 & 4.7351 & 6.2151 \\
Correlation & 0.2459 & -0.0590 & 0.0410 \\
Obs. & 31 & 205 & 236 \\
\hline \hline
\end{tabular}

Note: This table presents summary statistics on the unexpected changes in the Fed funds rate and changes in credit spreads during economic recessions, expansions as well as over the whole sample. The row "Correlation" presents the coefficients of correlation between the unexpected changes in the Fed funds rate and the variable of interest. The business cycles are defined based on a dummy variable that takes the value 1 in month $t$ if the economy is in a recession as defined by the NBER and zero otherwise. 
Table 3: Summary Statistics over the Credit Cycle

Unexpected Change $\left(U_{t}\right)$

\begin{tabular}{lccc}
\hline \hline & Widening & Narrowing & Whole sample \\
\hline Mean & -3.7472 & -2.9097 & -3.3037 \\
Std. Dev. & 10.7667 & 9.4068 & 10.0563 \\
Correlation & 1.0000 & 1.0000 & 1.0000 \\
Obs. & 111 & 125 & 236 \\
\hline \hline
\end{tabular}

$$
\triangle(B A A-A A A)
$$

\begin{tabular}{lccc}
\hline \hline & Widening & Narrowing & Whole sample \\
\hline Mean & 6.6942 & -3.8952 & 1.0854 \\
Std. Dev. & 11.0746 & 3.4632 & 9.5809 \\
Correlation & 0.1618 & 0.1281 & 0.1075 \\
Obs. & 111 & 125 & 236 \\
\hline \hline
\end{tabular}

$$
\triangle(B A A-A A)
$$

\begin{tabular}{lccc}
\hline \hline & Widening & Narrowing & Whole sample \\
\hline Mean & 5.6216 & -3.7528 & 0.8125 \\
Std. Dev. & 8.8290 & 3.2727 & 8.0830 \\
Correlation & 0.1394 & 0.0534 & 0.0864 \\
Obs. & 115 & 121 & 236 \\
\hline \hline
\end{tabular}

$\Delta(B A A-A)$

\begin{tabular}{lccc}
\hline \hline & Widening & Narrowing & Whole sample \\
\hline Mean & 4.6940 & -3.3308 & 0.5456 \\
Std. Dev & 5.9265 & 3.2945 & 10.2151 \\
Correlation & 0.0739 & 0.0962 & 0.0410 \\
Obs. & 114 & 122 & 236 \\
\hline \hline
\end{tabular}

Note: This table presents summary statistics on the unexpected changes in the Fed funds rate and changes in credit spreads during periods of widening and narrowing credit spreads as well as over the whole sample. The row "Correlation" presents the coefficients of correlation between the unexpected changes in the Fed funds rate and the variable of interest. A given month is considered to be a period of widening (narrowing) credit spreads if the change in a given credit spread is positive (negative) in that month. For the purpose of calculating the summary statistics for the unexpected changes in the Fed funds rate over the credit cycle, a given month is considered to be a period of widening credit spreads if at least two of the three credit spreads widen during that month. Otherwise, it is considered to be a period of narrowing credit spreads. 
Table 4: Summary Statistics over the Monetary Cycle

Unexpected Change $\left(U_{t}\right)$

\begin{tabular}{lcccc}
\hline \hline & Expansionary & Contractionary & Neutral & Whole sample \\
\hline Mean & -11.7754 & 0.7745 & -1.5987 & -3.3037 \\
Std. Dev. & 15.6709 & 5.5255 & 6.7750 & 10.0563 \\
Correlation & 1.0000 & 1.0000 & 1.0000 & 1.0000 \\
Obs. & 47 & 32 & 157 & 236 \\
\hline \hline
\end{tabular}

$\Delta(B A A-A A A)$

\begin{tabular}{lcccc}
\hline \hline & Expansionary & Contractionary & Neutral & Whole sample \\
\hline Mean & 5.0283 & 1.0944 & -0.0968 & 1.0854 \\
Std. Dev. & 16.4456 & 5.2000 & 6.8603 & 9.5809 \\
Correlation & 0.2181 & -0.2382 & 0.2685 & 0.1075 \\
Obs. & 47 & 32 & 157 & 236 \\
\hline \hline
\end{tabular}

$\Delta(B A A-A A)$

\begin{tabular}{lcccc}
\hline \hline & Expansionary & Contractionary & Neutral & Whole sample \\
\hline Mean & 3.1440 & 0.9462 & 0.0913 & 0.8152 \\
Std. Dev. & 12.7539 & 6.0869 & 6.3975 & 8.0830 \\
Correlation & 0.1490 & -0.2098 & 0.2372 & 0.0864 \\
Obs. & 47 & 32 & 157 & 236 \\
\hline \hline
\end{tabular}

$\triangle(B A A-A)$

\begin{tabular}{lcccc}
\hline \hline & Expansionary & Contractionary & Neutral & Whole sample \\
\hline Mean & 2.2600 & 0.8137 & -0.0223 & 0.5456 \\
Std. Dev. & 9.1065 & 4.5653 & 5.3263 & 6.2151 \\
Correlation & 0.1579 & -0.1423 & 0.0847 & 0.0410 \\
Obs. & 47 & 32 & 157 & 236 \\
\hline \hline
\end{tabular}

Note: This table presents summary statistics on the unexpected changes in the Fed funds rate and changes in credit spreads during expansionary, contractionary and neutral monetary policy cycles as well as over the whole sample. The row "Correlation" presents the coefficients of correlation between the unexpected changes in the Fed funds rate and the variable of interest. The expansionary, contractionary and neutral monetary policy cycles correspond to periods of negative, positive and zero actual changes in the Fed funds rate, respectively. 
Table 5: The Effect of Economic News on Unexpected Changes in the Fed Funds Rate and Credit Spreads

\begin{tabular}{lcccc}
\hline \hline & $U_{t}$ & $\Delta(B A A-A A A)$ & $\Delta(B A A-A A)$ & $\Delta(B A A-A)$ \\
\hline Headline CPI & -0.2234 & $1.1269 *$ & $1.3307 * *$ & $1.1071^{* *}$ \\
Core CPI & -0.8658 & -0.4902 & -0.4416 & -0.7634 \\
Headline PPI & 0.6460 & -0.3420 & -0.0271 & -0.4263 \\
Core PPI & $-1.8016^{*}$ & 0.6662 & -0.0292 & 0.0058 \\
Nonfarm Payrolls & $1.7488^{*}$ & -0.2115 & -0.0074 & -0.1335 \\
Industrial Production & 1.2492 & -0.1288 & -0.1658 & -0.2410 \\
Retail Sales & -1.0400 & 0.3270 & 0.4857 & 0.4190 \\
Retail Sales, ex. Autos & 0.4104 & $-1.1947 * *$ & -0.3908 & -0.2063 \\
& & & & \\
\hline Adjusted-R & $4.3894 \%$ & $-0.1439 \%$ & $0.1902 \%$ & $-0.2893 \%$ \\
\hline \hline
\end{tabular}

Note: This table presents coefficient estimates from a regression of the variable listed in the column headings on a constant and news about the variables listed in rows. The news variable for each macroeconomic variable is calculated as the difference between the actual realization and the expected value from MMS database standardized by their corresponding mean. The coefficients are estimated via OLS with HAC standard errors. $* * *$ denotes significance at $1 \%$ confidence level, $* *$ denotes significance at $5 \%$ confidence level, $*$ denotes significance at $10 \%$ confidence level.

Table 6: The Effect of Changes in Macroeconomic Variables on Unexpected Changes in the Fed Funds Rate and Credit Spreads

\begin{tabular}{lcccc}
\hline \hline & $U_{t}$ & $\Delta(B A A-A A A)$ & $\Delta(B A A-A A)$ & $\Delta(B A A-A)$ \\
\hline CPI & -2.0533 & -1.1322 & -0.1353 & -0.4381 \\
PPI & 0.6974 & $-4.0922^{*}$ & $-3.4546^{*}$ & -2.1255 \\
Nonfarm Payrolls & 0.0284 & $-2.4429^{*}$ & -1.7520 & -1.0701 \\
Industrial Production & -1.1208 & 0.4773 & 0.0954 & -0.2252 \\
Retail Sales & -0.4472 & $-3.1382^{* *}$ & $-2.5243^{*}$ & $-2.0335^{* *}$ \\
Retail Sales, ex. Autos & 0.3767 & $2.6878^{*}$ & $2.2599^{*}$ & $1.9146^{* *}$ \\
& & & & \\
\hline Adjusted-R & & & $21.5726 \%$ & $17.9521 \%$ \\
\hline \hline
\end{tabular}

Note: This table presents coefficient estimates from a regression of the variable listed in the column headings on a constant and monthly changes in the variables listed in rows. The coefficients are estimated via OLS with HAC standard errors. *** denotes significance at $1 \%$ confidence level, ** denotes significance at $5 \%$ confidence level, * denotes significance at $10 \%$ confidence level. 
Table 7: The Effect of Unexpected Changes in the Fed Funds Rate on Credit Spreads using Ex-post Business Cycle Indicators

$$
\Delta \text { Spread }_{t}=\beta_{0}+\beta_{1} U_{t}+\beta_{2} B C I_{t}+\beta_{3}\left(U_{t} \times B C I_{t}\right)+\varepsilon_{t}
$$

\section{Panel A}

\begin{tabular}{lccc}
\hline \hline Variable & $\Delta(B A A-A A A)$ & $\Delta(B A A-A A)$ & $\Delta(B A A-A)$ \\
\hline \multirow{2}{*}{ Constant } & -0.0042 & -0.2188 & \\
$U_{t}$ & 0.0210 & 0.0052 & -0.2091 \\
$N B E R_{t}$ & $10.4890^{* *}$ & $9.3717^{* * *}$ & -0.0337 \\
$U_{t} \times N B E R_{t}$ & $0.2794^{* *}$ & $0.2293^{* *}$ & $6.0275^{* * *}$ \\
& & & $0.1897^{* *}$ \\
\hline Adjusted- $R^{2}$ & $12.4754 \%$ & $13.5069 \%$ & $8.9824 \%$ \\
\hline \hline
\end{tabular}

Panel B

\begin{tabular}{lccc}
\hline \hline Variable & $\Delta(B A A-A A A)$ & $\Delta(B A A-A A)$ & $\Delta(B A A-A)$ \\
\hline & & & \\
Constant & $1.4542 * * *$ & $1.0890^{* *}$ & $0.7030^{*}$ \\
$U_{t}$ & 0.0355 & 0.0224 & -0.0126 \\
$\Delta \ln \left(I P_{t}\right)$ & $-2.9732^{* * *}$ & $-2.2292^{* * *}$ & $-2.0292^{* * *}$ \\
$U_{t} \times \Delta \ln \left(I P_{t}\right)$ & $-0.3969^{*}$ & $-0.2786^{*}$ & $-0.2244^{* *}$ \\
& & & \\
\hline Adjusted- $R^{2}$ & $12.1322 \%$ & $8.2503 \%$ & $9.2761 \%$ \\
\hline \hline
\end{tabular}

Note: This table presents the effect of unexpected changes in the Fed funds rate on changes in credit spreads over the business cycle using ex-post measures of business conditions. $U_{t}$ is the unexpected change in the Fed funds rate in month $t, N B E R_{t}$ is a dummy variable that takes the value 1 in month $t$ if the economy is in a recession as defined by the NBER and zero otherwise. $I P_{t}$ is the level of the industrial production index in month $t$. The coefficients are estimated via OLS with HAC standard errors. *** denotes significance at $1 \%$ confidence level, $* *$ denotes significance at $5 \%$ confidence level, $*$ denotes significance at $10 \%$ confidence level. 
Table 8: The Effect of Unexpected Changes in the Fed Funds Rate on Credit Spreads using Real-Time Business Cycle Indicators

$$
\Delta \text { Spread }_{t}=\beta_{0}+\beta_{1} U_{t}+\beta_{2} B C I_{t}+\beta_{3}\left(U_{t} \times B C I_{t}\right)+\varepsilon_{t}
$$

Panel A

\begin{tabular}{lccc}
\hline \hline Variable & $\Delta(B A A-A A A)$ & $\Delta(B A A-A A)$ & $\Delta(B A A-A)$ \\
\hline \multirow{2}{*}{ Constant } & -0.8186 & -0.3593 & \\
$U_{t}$ & 0.0234 & 0.0323 & -0.3434 \\
Prob $_{1, t}$ & $20.4725^{* *}$ & 12.9609 & -0.0291 \\
$U_{t} \times$ Prob $_{1, t}$ & $0.4360^{* * *}$ & $0.2392^{*}$ & 8.6480 \\
& & & $0.2442^{* *}$ \\
\hline Adjusted- $R^{2}$ & $17.333 \%$ & $9.2595 \%$ & $6.5444 \%$ \\
\hline \hline
\end{tabular}

Panel B

\begin{tabular}{lccc}
\hline \hline Variable & $\Delta(B A A-A A A)$ & $\Delta(B A A-A A)$ & $\Delta(B A A-A)$ \\
\hline \multirow{2}{*}{ Constant } & & & \\
$U_{t}$ & 0.6862 & -0.6351 & -0.5298 \\
Prob $_{2, t}$ & $16.2577^{* *}$ & 0.0248 & -0.0188 \\
$U_{t} \times$ Prob $_{2, t}$ & $0.2985^{*}$ & $13.1660^{* * *}$ & $8.9061^{* * *}$ \\
& & 0.1922 & 0.1690 \\
\hline Adjusted- $R^{2}$ & $17.2415 \%$ & & $11.2794 \%$ \\
\hline \hline
\end{tabular}

Note: This table presents the effect of unexpected changes in the Fed funds rate on changes in credit spreads over the business cycle using real-time measures of business conditions. $U_{t}$ is the unexpected change in the Fed funds rate in month $t, \operatorname{Prob} 1, t$ in Panel A is the real-time recession probability from the estimation of Equation (5) and $\operatorname{Prob}_{2, t}$ in Panel B is the real-time recession probability from Chauvet and Piger (2008). The coefficients are estimated via OLS with HAC standard errors. $* * *$ denotes significance at $1 \%$ confidence level, $* *$ denotes significance at $5 \%$ confidence level, * denotes significance at $10 \%$ confidence level. 
Table 9: Credit Spreads and Instrumental Variables

\section{$\triangle(B A A-A A A)$}

\section{Constant}

$\Delta e m p_{t-1}$

$\Delta \ln \left(I P_{t-1}\right)$

$\Delta c p i_{t-1}$

$\Delta$ house $_{t-1}$
$3.7563 *$

$-6.9008$

$-4.4346$

$-2.7487$

4.2904

$\triangle(B A A-A A)$

2.2274

$-3.6808$

$-3.7950$

$-0.7713$

4.3133
$\Delta(B A A-A)$

1.8109

$-3.0232$

$-2.5050$

$-1.2009$

1.4160

Note: This table presents coefficient estimates from a simple linear regression of credit spread changes on instrumental variables. The coefficients are estimated via OLS with HAC standard errors. $\Delta e m p_{t-1}$ is the lagged change in employment numbers divided by 1000 , $\Delta \ln \left(I P_{t-1}\right)$ is the lagged percentage log change in the industrial production index, $\Delta c p i_{t-1}$ is the lagged change in basis points in the seasonally adjusted consumer price index and $\Delta$ house $e_{t-1}$ is the lagged change in the housing starts divided by 1000 . All instrumental variables are available from the Federal Reserve Bank of St. Louis. $* * *$ denotes significance at $1 \%$ confidence level, $* *$ denotes significance at $5 \%$ confidence level, * denotes significance at $10 \%$ confidence level.

Table 10: First Stage of the Two Stage Least Squares Estimation of Equation (7)

\begin{tabular}{|c|c|c|c|c|}
\hline & $\overline{N N B E R_{t}}$ & 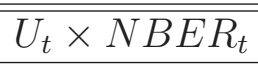 & 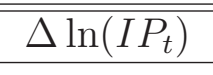 & $\overline{U_{t} \times \Delta \ln \left(I P_{t}\right)}$ \\
\hline Constant & $0.2015^{* * *}$ & -0.2863 & 0.0872 & $-1.0192 *$ \\
\hline$U_{t}$ & 0.0003 & 0.3733 & $-0.0041 * * *$ & $-0.1681 * * *$ \\
\hline$\Delta e m p_{t-1}$ & $-0.8680 * * *$ & $-1.1549 * * *$ & 1.0596 & 1.5585 \\
\hline$\Delta \ln \left(I P_{t-1}\right)$ & -0.0532 & 0.3858 & -0.0904 & 0.6423 \\
\hline$\Delta c p i_{t-1}$ & $0.0822 * *$ & 0.7284 & -0.0369 & $1.5199 *$ \\
\hline$\Delta$ house $_{t-1}$ & -0.1645 & 0.9876 & 0.6070 & -1.4295 \\
\hline$U_{t} \times \Delta e m p_{t-1}$ & 0.0099 & -1.8594 & $-0.0405 * * *$ & $2.2266 * * *$ \\
\hline$U_{t} \times \Delta \ln \left(I P_{t-1}\right)$ & $0.0056^{* *}$ & -0.0643 & $0.0026^{*}$ & -0.0501 \\
\hline$U_{t} \times \Delta c p i_{t-1}$ & $-0.0067^{*}$ & $0.0857 * * *$ & $0.0264 *$ & 0.0738 \\
\hline$U_{t} \times \Delta$ house $_{t-1}$ & 0.0185 & -0.2713 & 0.0030 & 0.0728 \\
\hline$\overline{g_{\min }}$ & \multicolumn{2}{|c|}{16.2751} & \multicolumn{2}{|r|}{5.9797} \\
\hline$\widehat{B}_{\max }$ & \multicolumn{2}{|c|}{0.5963} & \multicolumn{2}{|r|}{0.1614} \\
\hline$\widetilde{B}_{\max }$ & \multicolumn{2}{|c|}{0.0614} & \multicolumn{2}{|r|}{0.1672} \\
\hline
\end{tabular}

Note: This table presents coefficient estimates from the first stage of a two stage least squares estimation of the empirical model in Equation (7) where the variables $B C I_{t}$ and $U_{t} \times B C I_{t}$ might be endogenous. The first stage is a regression of the possibly endogenous variables listed in the column headings on instrumental variables listed in rows. $g_{\min }$ is the Cragg-Donald statistic discussed in Stock and Yogo (2005) testing the null hypothesis that the instruments are weak. $\widehat{B}_{\max }$ and $\widetilde{B}_{\max }$ are the maximal relative bias measures of the TSLS estimators used in determining the critical values for the Cragg-Donald statistics. The significance of this test statistic is discussed in the text. *** denotes significance at $1 \%$ confidence level, $* *$ denotes significance at $5 \%$ confidence level, $*$ denotes significance at $10 \%$ confidence level. 
Table 11: Durbin-Wu-Hausman Test of Endogeneity

Panel A

\begin{tabular}{lccc}
\hline \hline & $\Delta(B A A-A A A)$ & $\Delta(B A A-A A)$ & $\Delta(B A A-A)$ \\
\hline$F_{D W H, 1}$ & $14.4112^{* * *}$ & $7.4898^{* * *}$ & $7.8672 * *$ \\
$F_{D W H, 2}$ & $15.4176^{* * *}$ & $7.7852^{* * *}$ & $8.1487 * *$ \\
$F_{D W H, 3}$ & $17.3381^{* * *}$ & $8.1868 * *$ & $8.6704 * *$ \\
& & & \\
\hline \hline
\end{tabular}

Panel B

\begin{tabular}{lccc}
\hline \hline & $\Delta(B A A-A A A)$ & $\Delta(B A A-A A)$ & $\Delta(B A A-A)$ \\
\hline$F_{D W H, 1}$ & 3.6293 & 1.3657 & 0.7674 \\
$F_{D W H, 2}$ & 3.6933 & 1.3811 & 0.7706 \\
$F_{D W H, 3}$ & 3.9849 & 1.4056 & 0.7821 \\
\hline
\end{tabular}

Note: This table presents the three Durbin-Wu-Hausman tests of endogeneity discussed in Staiger and Stock (1997). A statistically significant F-statistic rejects the null hypothesis of exogeneity and suggests that the variable is endogenous. Staiger and Stock (1997) suggest using the $F_{D W H, 3}$ statistic when the instruments are weak. Panel A presents the test statistics for the NBER dummy variable as the business cycle indicator. Panel B presents the test statistics for the growth rate of industrial production as the business cycle indicator. *** denotes significance at $1 \%$ confidence level, $* *$ denotes significance at $5 \%$ confidence level, $*$ denotes significance at $10 \%$ confidence level. 
Table 12: The Effect of Unexpected Changes in the Fed Funds Rate on Credit Spreads in a Two-Stage Least Squares Framework

$$
\Delta \text { Spread }_{t}=\beta_{0}+\beta_{1} U_{t}+\beta_{2} B C I_{t}+\beta_{3}\left(U_{t} \times B C I_{t}\right)+\nu_{t}
$$

Panel A

\begin{tabular}{lccc}
\hline \hline & $\Delta(B A A-A A A)$ & $\Delta(B A A-A A)$ & $\Delta(B A A-A)$ \\
\hline \multirow{3}{*}{ Constant } & & & \\
$U_{t}$ & -1.2150 & -0.8006 & -0.8020 \\
$N B E R_{t}$ & 0.0180 & 0.0301 & -0.0440 \\
$U_{t} \times N B E R_{t}$ & $20.1472^{* * *}$ & $14.3166^{* * *}$ & $10.6550^{* * *}$ \\
& $0.3660^{* *}$ & 0.2111 & $0.2520^{* *}$ \\
\hline \hline
\end{tabular}

\section{Panel B}

$\triangle(B A A-A A A) \quad \Delta(B A A-A A) \quad \Delta(B A A-A)$

$\begin{array}{lccc}\text { Constant } & 2.1407 * * * & 1.3721 * * & 0.8962 * \\ U_{t} & 0.0431 & 0.0351 & -0.0113 \\ \Delta \ln \left(I P_{t}\right) & -6.7827 * * * & -3.4026 * & -3.1330 * * \\ U_{t} \times \Delta \ln \left(I P_{t}\right) & -0.3382 * * * & -0.1979 * * & -0.2125 * * *\end{array}$

Note: This table presents the effect of unexpected changes in the Fed funds rate on changes in credit spreads over the business cycle in a two stage least squares framework where the business cycle indicators are instrumented by variables listed in rows in Table 10 . *** denotes significance at $1 \%$ confidence level, $* *$ denotes significance at $5 \%$ confidence level, $*$ denotes significance at $10 \%$ confidence level. 
Table 13: The Effect of Unexpected Changes in the Fed Funds Rate on Credit Spreads over the Business Cycle with Control Variables

$$
\begin{aligned}
\Delta \text { Spread }_{t}= & \beta_{0}+\beta_{1} U_{t}+\beta_{2} B C I_{t}+\beta_{3}\left(U_{t} \times B C I_{t}\right)+\beta_{4} \Delta r_{10, t}+\beta_{5}\left(\Delta r_{10, t}\right)^{2} \\
& +\beta_{6} \Delta\left(r_{10, t}-r_{2, t}\right)+\beta_{7} \Delta V I X_{t}+\beta_{8} S P 500_{t}+\varepsilon_{t}
\end{aligned}
$$

\begin{tabular}{lccc}
\hline \hline Variable & $\Delta(B A A-A A A)$ & $\Delta(B A A-A A)$ & $\Delta(B A A-A)$ \\
\hline Constant & -0.3809 & -0.1369 & -0.2976 \\
& & & \\
$U_{t}$ & 0.0450 & 0.0209 & -0.0324 \\
$N B E R_{t}$ & $8.2080^{* *}$ & $7.3251^{* * *}$ & $4.5512^{* * *}$ \\
$U_{t} \times N B E R_{t}$ & $0.2278^{*}$ & $0.2007 * *$ & $0.1618^{*}$ \\
& & & \\
$\Delta r_{10, t}$ & -0.0225 & -0.0040 & -0.0053 \\
$\left(\Delta r_{10, t}\right)^{2}$ & $0.0013^{*}$ & 0.0006 & 0.0007 \\
$\Delta\left(r_{10, t}-r_{2, t}\right)$ & 0.0786 & 0.0915 & 0.0445 \\
$\Delta V I X$ & 0.2355 & 0.1273 & 0.0798 \\
$S P 500$ & -25.3228 & -28.7757 & -24.0726 \\
& & & $12.7707 \%$ \\
\hline Adjusted- $R^{2}$ & $17.2443 \%$ & $18.9781 \%$ & \\
\hline \hline
\end{tabular}

Note: This table presents the effect of unexpected changes in the Fed funds rate on changes in credit spreads over the business cycle where we control for other variables that might affect credit spreads. $U_{t}$ is the monthly unexpected changes in the Fed funds rate, $N B E R_{t}$ is a dummy variable that takes the value 1 in month $t$ if the economy is in a recession as defined by the NBER and zero otherwise. $r_{10, t}$ and $r_{2, t}$ are the yields on the ten and two year treasury bonds, respectively. $V I X_{t}$ is a volatility index based on implied volatility from S\&P 500 index options traded on Chicago Board of Option Exchange. $S P 500_{t}$ is the monthly return on the S\&P 500 index. The coefficient estimates are from an OLS estimation with HAC standard errors. $* * *$ denotes significance at $1 \%$ confidence level, $* *$ denotes significance at $5 \%$ confidence level, * denotes significance at $10 \%$ confidence level. 
Table 14: The Effect of Unexpected Changes in the Fed Funds Rate on Credit Spreads over the Business Cycle with Control Variables

$$
\begin{aligned}
\Delta \text { Spread }_{t}= & \beta_{0}+\beta_{1} U_{t}+\beta_{2} B C I_{t}+\beta_{3}\left(U_{t} \times B C I_{t}\right)+\beta_{4} \Delta r_{10, t}+\beta_{5}\left(\Delta r_{10, t}\right)^{2} \\
& +\beta_{6} \Delta\left(r_{10, t}-r_{2, t}\right)+\beta_{7} \Delta V I X_{t}+\beta_{8} S P 500_{t}+\varepsilon_{t}
\end{aligned}
$$

\begin{tabular}{lccc}
\hline \hline Variable & $\Delta(B A A-A A A)$ & $\Delta(B A A-A A)$ & $\Delta(B A A-A)$ \\
\hline Constant & -0.9464 & -0.1130 & -0.2968 \\
& & & \\
$U_{t}$ & 0.0479 & 0.0496 & -0.0260 \\
Prob $_{1, t}$ & $18.0807^{* *}$ & 10.4310 & 6.6087 \\
$U_{t} \times \operatorname{Prob}_{1, t}$ & $0.4058^{* *}$ & 0.2171 & $0.2127^{*}$ \\
& & & -0.0085 \\
$\Delta r_{10, t}$ & -0.0244 & -0.0108 & 0.0006 \\
$\left(\Delta r_{10, t}\right)^{2}$ & 0.0008 & 0.0004 & $0.0588^{*}$ \\
$\Delta\left(r_{10, t}-r_{2, t}\right)$ & 0.0927 & $0.1148^{* *}$ & 0.0573 \\
$\Delta V I X$ & 0.2626 & 0.0778 & $-27.7984^{* *}$ \\
$S P 500$ & -23.8582 & $-35.3746^{* *}$ & \\
\hline Adjusted- $R^{2}$ & & & $11.7989 \%$ \\
\hline \hline
\end{tabular}

Note: This table presents the effect of unexpected changes in the Fed funds rate on changes in credit spreads over the business cycle where we control for other variables that might affect credit spreads. $U_{t}$ is the monthly unexpected changes in the Fed funds rate, Prob $_{1, t}$ is the real-time recession probability. $r_{10, t}$ and $r_{2, t}$ are the yields on the ten and two year treasury bonds, respectively. $V I X_{t}$ is a volatility index based on implied volatility from S\&P 500 index options traded on Chicago Board of Option Exchange. $S P 500_{t}$ is the monthly return on the S\&P 500 index. The coefficient estimates are from an OLS estimation with HAC standard errors. *** denotes significance at $1 \%$ confidence level, ** denotes significance at $5 \%$ confidence level, * denotes significance at $10 \%$ confidence level. 
Table 15: The Effect of Unexpected Changes in the Fed Funds Rate on Industry Specific Credit Spreads over the Business Cycle

$$
\begin{aligned}
\Delta \text { Spread }_{t}= & \beta_{0}+\beta_{1} U_{t}+\beta_{2} B C I_{t}+\beta_{3}\left(U_{t} \times B C I_{t}\right)+\beta_{4} \Delta r_{10, t}+\beta_{5}\left(\Delta r_{10, t}\right)^{2} \\
& +\beta_{6} \Delta\left(r_{10, t}-r_{2, t}\right)+\beta_{7} \Delta V I X_{t}+\beta_{8} S P 500_{t}+\varepsilon_{t}
\end{aligned}
$$

Panel A : Utilities

\begin{tabular}{lcc}
\hline \hline Variable & $\Delta(B A A-A A)$ & $\Delta(B A A-A)$ \\
\hline Constant & 0.0657 & -0.3033 \\
$U_{t}$ & 0.0181 & -0.0329 \\
$N B E R_{t}$ & $7.8329^{* * *}$ & $5.5866^{* *}$ \\
$U_{t} \times N B E R_{t}$ & $0.2782^{*}$ & $0.2534^{* *}$ \\
$\cdot$ & & \\
$\cdot$ & & \\
\hline Adjusted- $R^{2}$ & $11.3371 \%$ & $10.8624 \%$ \\
\hline \hline
\end{tabular}

Panel B : Industrial Goods

\begin{tabular}{lcc}
\hline \hline Variable & $\Delta(B A A-A A)$ & $\Delta(B A A-A)$ \\
\hline
\end{tabular}

Constant

$-0.8459$

$-0.7940$

$U_{t}$

$-0.0511$

$-0.0981 * *$

$N B E R_{t}$

$8.2050 * * *$

$4.8696^{* *}$

$U_{t} \times N B E R_{t}$

$0.2688 * *$

0.2123

.

\begin{tabular}{lll}
\hline Adjusted- $R^{2}$ & $17.1523 \%$ & $8.3293 \%$ \\
\hline \hline
\end{tabular}

Note: This table presents the effect of unexpected changes in the Fed funds rate on changes in credit spreads in utilities (Panel A) and industrial goods (Panel B) industries over the business cycle where we control for other variables that might affect credit spreads. $U_{t}$ is the monthly unexpected change in the Fed funds rate, $N B E R_{t}$ is a dummy variable that takes the value 1 in month $t$ if the economy is in a recession as defined by the NBER and zero otherwise. The control variables which are suppressed are changes in the yield on the 10-year treasury bond, change in the slope and curvature of the yield curve, change in the VIX Index and the monthly return on the S\&P 500 index. The coefficient estimates are from an OLS estimation with HAC standard errors. *** denotes significance at $1 \%$ confidence level, ** denotes significance at $5 \%$ confidence level, $*$ denotes significance at $10 \%$ confidence level. 
Table 16: The Effect of Unexpected Changes in the Fed Funds Rate on Industry Specific Credit Spreads over the Business Cycle

$$
\begin{aligned}
\Delta \text { Spread }_{t}= & \beta_{0}+\beta_{1} U_{t}+\beta_{2} B C I_{t}+\beta_{3}\left(U_{t} \times B C I_{t}\right)+\beta_{4} \Delta r_{10, t}+\beta_{5}\left(\Delta r_{10, t}\right)^{2} \\
& +\beta_{6} \Delta\left(r_{10, t}-r_{2, t}\right)+\beta_{7} \Delta V I X_{t}+\beta_{8} S P 500_{t}+\varepsilon_{t}
\end{aligned}
$$

Panel A : Utilities

\begin{tabular}{lcc}
\hline \hline Variable & $\Delta(B A A-A A)$ & $\Delta(B A A-A)$ \\
\hline Constant & -0.4305 & -0.7013 \\
$U_{t}$ & 0.0182 & -0.0430 \\
Prob $_{1, t}$ & $16.8877^{* *}$ & $12.5731^{* * *}$ \\
$U_{t} \times \operatorname{Prob}_{1, t}$ & $0.4643^{* *}$ & $0.4324^{* *}$ \\
$\cdot$ & & \\
$\cdot$ & & \\
\hline Adjusted- $R^{2}$ & $16.4173 \%$ & $16.4902 \%$ \\
\hline \hline
\end{tabular}

Panel B : Industrial Goods

\begin{tabular}{lcc}
\hline \hline Variable & $\Delta(B A A-A A)$ & $\Delta(B A A-A)$ \\
\hline Constant & -0.4818 & -0.5810 \\
$U_{t}$ & -0.0085 & $-0.0900^{*}$ \\
Prob $_{1, t}$ & 8.0915 & 4.7826 \\
$U_{t} \times \operatorname{Prob}_{1, t}$ & 0.2236 & 0.2433 \\
$\cdot$ & & \\
$\cdot$ & & \\
\hline Adjusted- $R^{2}$ & $13.0965 \%$ & $6.4450 \%$ \\
\hline \hline
\end{tabular}

Note: This table presents the effect of unexpected changes in the Fed funds rate on changes in credit spreads in utilities (Panel A) and industrial goods (Panel B) industries over the business cycle where we control for other variables that might affect credit spreads. $U_{t}$ is the monthly unexpected change in the Fed funds rate, $\operatorname{Prob}_{1, t}$ is the real-time recession probability. The control variables which are suppressed are changes in the yield on the 10-year treasury bond, change in the slope and curvature of the yield curve, change in the VIX Index and the monthly return on the S\&P 500 index. The coefficient estimates are from an OLS estimation with HAC standard errors. *** denotes significance at $1 \%$ confidence level, $* *$ denotes significance at $5 \%$ confidence level, $*$ denotes significance at $10 \%$ confidence level. 
Table 17: The Effect of Unexpected Changes in the Fed Funds Rate on Credit Spreads over the Business Cycle in an EGARCH Framework

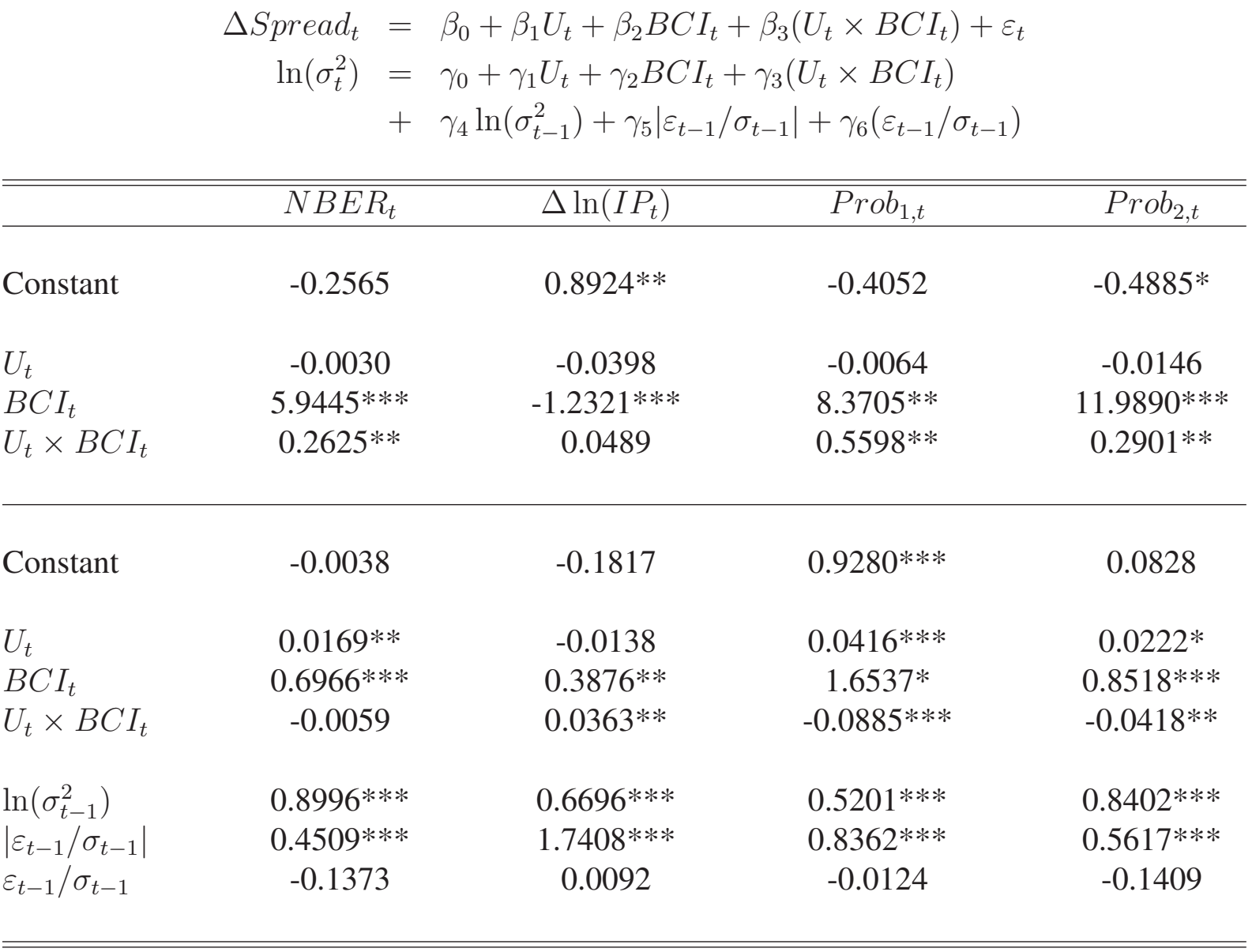

Note: This table presents the effect of unexpected changes in the Fed funds rate on changes in credit spreads over the business cycle in an EGARCH framework. The coefficient estimates are from a maximum likelihood estimation with Bollerslev-Wooldridge HAC standard errors. *** denotes significance at $1 \%$ confidence level, $* *$ denotes significance at $5 \%$ confidence level, $*$ denotes significance at $10 \%$ confidence level. 
Table 18: The Effect of Unexpected Changes in the Fed Funds Rate on Credit Spreads over the Credit Cycle

Coefficient Estimates in State 0

\begin{tabular}{lccc}
\hline \hline & $\Delta(B A A-A A A)$ & $\Delta(B A A-A A)$ & $\Delta(B A A-A)$ \\
\hline Constant & -0.7101 & -0.6059 & -0.4494 \\
$U_{t}$ & -0.0364 & -0.0224 & $-0.0577 * *$ \\
\hline \hline
\end{tabular}

Coefficient Estimates in State 1

\begin{tabular}{lccc}
\hline \hline & $\Delta(B A A-A A A)$ & $\Delta(B A A-A A)$ & $\Delta(B A A-A)$ \\
\hline Constant & $6.9065^{* * *}$ & $5.3956^{* *}$ & $3.3067^{* *}$ \\
$U_{t}$ & $0.4047^{*}$ & 0.2524 & 0.2204 \\
\hline \hline
\end{tabular}

Variance Matrix in State 0

\begin{tabular}{lccc}
\hline \hline & $\Delta(B A A-A A A)$ & $\Delta(B A A-A A)$ & $\Delta(B A A-A)$ \\
\hline$\triangle(B A A-A A A)$ & $19.6490^{* * *}$ & $14.2643 * * *$ & $11.9174 * * *$ \\
$\triangle(B A A-A A)$ & $14.2643^{* * *}$ & $16.6222^{* * *}$ & $12.7072 * * *$ \\
$\Delta(B A A-A)$ & $11.9174 * * *$ & $12.7072 * * *$ & $12.3926 * * *$ \\
\hline \hline
\end{tabular}

Variance Matrix in State 1

\begin{tabular}{lccc}
\hline \hline & $\Delta(B A A-A A A)$ & $\Delta(B A A-A A)$ & $\Delta(B A A-A)$ \\
\hline$\triangle(B A A-A A A)$ & $264.0661^{* * * *}$ & $187.2578^{* * *}$ & $130.8360^{* * *}$ \\
$\Delta(B A A-A A)$ & $187.2578^{* * *}$ & $187.4663^{* * *}$ & $125.4650^{* * *}$ \\
$\Delta(B A A-A)$ & $130.8360^{* * *}$ & $125.4650^{* * *}$ & $106.6662^{* * *}$ \\
\hline \hline
\end{tabular}

Transition Probability Matrix

\begin{tabular}{lcc}
\hline \hline & State 0 & State 1 \\
\hline State 0 & $0.8782^{* * *}$ & $0.3775^{* * *}$ \\
State 1 & $0.1218^{* * *}$ & $0.6225^{* * *}$ \\
\hline \hline
\end{tabular}

Note: This table presents the effect of unexpected changes in the Fed funds rate on changes in credit spreads where the state variable is determined jointly by credit spreads. The coefficient estimates are obtained from the MLE estimation of the Markov regime switching model in Equation (10). $U_{t}$ is the unexpected change in the Fed funds rate. State 0 corresponds to narrowing credit spreads and State 1 corresponds to widening credit spreads. $* * *$ denotes significance at $1 \%$ confidence level, $* *$ denotes significance at $5 \%$ confidence level, $*$ denotes significance at $10 \%$ confidence level. 
Table 19: The Effect of Unexpected Changes in the Fed Funds Rate on Changes in Credit Spreads over the Credit Cycle with Control Variables

Coefficient Estimates in State 0

\begin{tabular}{lccc}
\hline \hline & $\Delta(B A A-A A A)$ & $\Delta(B A A-A A)$ & $\Delta(B A A-A)$ \\
\hline Constant & $-0.7387^{*}$ & $-0.7654^{* *}$ & -0.3303 \\
$U_{t}$ & -0.0282 & 0.0098 & $-0.0480^{* *}$ \\
$\Delta r_{10, t}$ & $-0.0462^{* * *}$ & -0.0195 & -0.0131 \\
$\left(\Delta r_{10, t}\right)^{2}$ & 0.0002 & $0.0013^{* * *}$ & 0.0004 \\
$\Delta\left(r_{10, t}-r_{2, t}\right)$ & -0.0008 & $0.0504^{*}$ & 0.0237 \\
$\Delta V I X_{t}$ & -0.1064 & -0.1712 & -0.1235 \\
$S P 500_{t}$ & $-0.1968^{*}$ & $-0.2307^{* *}$ & $-0.2144^{* *}$ \\
\hline \hline
\end{tabular}

Coefficient Estimates in State 1

\begin{tabular}{lccc}
\hline \hline & $\Delta(B A A-A A A)$ & $\Delta(B A A-A A)$ & $\Delta(B A A-A)$ \\
\hline Constant & $5.1897^{* *}$ & $4.3252^{* *}$ & 2.2462 \\
$U_{t}$ & $0.4712^{* *}$ & 0.2493 & 0.2125 \\
$\Delta r_{10, t}$ & $0.1827^{* *}$ & 0.0499 & 0.0582 \\
$\left(\Delta r_{10, t}\right)^{2}$ & $0.0063^{* * *}$ & 0.0022 & $0.0023^{* *}$ \\
$\Delta\left(r_{10, t}-r_{2, t}\right)$ & $0.4418^{* * *}$ & $0.2770^{* *}$ & 0.1612 \\
$\Delta V I X_{t}$ & 0.9394 & 0.3216 & 0.3665 \\
$S P 500_{t}$ & -0.2560 & -0.7523 & -0.3997 \\
\hline \hline
\end{tabular}

Variance Matrix in State 0

\begin{tabular}{lccc}
\hline \hline & $\Delta(B A A-A A A)$ & $\Delta(B A A-A A)$ & $\Delta(B A A-A)$ \\
\hline$\Delta(B A A-A A A)$ & $18.4983 * * *$ & $12.6691 * * *$ & $10.9851 * * *$ \\
$\Delta(B A A-A A)$ & $12.6691 * * *$ & $15.3543 * * *$ & $11.9437 * * *$ \\
$\Delta(B A A-A)$ & $10.9851^{* * *}$ & $11.9437 * * *$ & $11.7480 * * *$ \\
\hline \hline
\end{tabular}

Variance Matrix in State 1

\begin{tabular}{lccc}
\hline \hline & $\Delta(B A A-A A A)$ & $\Delta(B A A-A A)$ & $\Delta(B A A-A)$ \\
\hline$\triangle(B A A-A A A)$ & $146.6848^{* * *}$ & $122.0137 * * *$ & $83.4390^{* * *}$ \\
$\Delta(B A A-A A)$ & $122.0137^{* * *}$ & $140.3600^{* * *}$ & $95.6840^{* * *}$ \\
$\Delta(B A A-A)$ & $83.4390^{* * *}$ & $95.6840^{* * *}$ & $86.9595 * * *$ \\
\hline \hline
\end{tabular}

Transition Probability Matrix

\begin{tabular}{lcc}
\hline \hline & State 0 & State 1 \\
\hline State 0 & $0.8510^{* * *}$ & $0.4687 * * *$ \\
State 1 & $0.1490^{* * *}$ & $0.5313 * * *$ \\
\hline \hline
\end{tabular}

Note: This table presents the effect of unexpected changes in the Fed funds rate on changes in credit spreads where the state variable is determined jointly by credit spreads. The coefficient estimates are obtained from the MLE estimation of the Markov regime switching model in Equation (11). $U_{t}$ is the unexpected change in the Fed funds rate. $r_{10, t}$ and $r_{2, t}$ are the yields on the ten and two year treasury bonds, respectively. VIX $X_{t}$ is a volatility index based on implied volatility from S\&P 500 index options traded on Chicago Board of Option Exchange. $S P 500_{t}$ is the monthly return on the S\&P 500 index. State 0 corresponds to narrowing credit spreads and State 1 corresponds to widening credit spreads. $* * *$ denotes significance at $1 \%$ confidence level, $* *$ denotes significance at $5 \%$ confidence level, $*$ denotes significance at $10 \%$ confidence level. 
Table 20: The Effect of Unexpected Changes in the Fed Funds Rate on Credit Spreads in the Industrial Goods Industry over the Credit Cycle

Coefficient Estimates in State 0

\begin{tabular}{lcc}
\hline \hline & $\Delta(B A A-A A)$ & $\Delta(B A A-A)$ \\
\hline Constant & $-0.9154^{* *}$ & 0.1851 \\
$U_{t}$ & -0.0544 & -0.0012 \\
\hline \hline
\end{tabular}

Coefficient Estimates in State 1

\begin{tabular}{lcc}
\hline \hline & $\Delta(B A A-A A)$ & $\Delta(B A A-A)$ \\
\hline Constant & $3.8448^{* *}$ & -1.4646 \\
$U_{t}$ & 0.0781 & -0.0826 \\
\hline \hline
\end{tabular}

Variance Matrix in State 0

\begin{tabular}{lcc}
\hline \hline & $\Delta(B A A-A A)$ & $\Delta(B A A-A)$ \\
\hline$\Delta(B A A-A A)$ & $15.6577^{* * *}$ & $-3.9700^{* * *}$ \\
$\triangle(B A A-A)$ & $-3.9700^{* * *}$ & $7.6620^{* * *}$ \\
\hline \hline
\end{tabular}

Variance Matrix in State 1

\begin{tabular}{lcc}
\hline \hline & $\Delta(B A A-A A)$ & $\Delta(B A A-A)$ \\
\hline$\triangle(B A A-A A)$ & $211.4192^{* * *}$ & $-62.0473 * * *$ \\
$\triangle(B A A-A)$ & $-62.0473^{* * *}$ & $62.3537 * * *$ \\
\hline \hline
\end{tabular}

Transition Probability Matrix

\begin{tabular}{lcc}
\hline \hline & State 0 & State 1 \\
\hline State 0 & $0.9200^{* * *}$ & $0.1159 * * *$ \\
State 1 & $0.0800^{* * *}$ & $0.8841^{* * *}$ \\
\hline \hline
\end{tabular}

Note: This table presents the effect of unexpected changes in the Fed funds rate on changes in credit spreads in the industrial goods industry where the state variable is determined jointly by credit spreads in the industrial goods industry. The coefficient estimates are obtained from the MLE estimation of the Markov regime switching model in Equation (10) without any control variables. $U_{t}$ is the unexpected change in the Fed funds rate. State 0 corresponds to narrowing credit spreads in the industrial goods industry and State 1 corresponds to widening credit spreads. $* * *$ denotes significance at $1 \%$ confidence level, $* *$ denotes significance at $5 \%$ confidence level, $*$ denotes significance at $10 \%$ confidence level. 
Table 21: The Effect of Unexpected Changes in the Fed Funds Rate on Credit Spreads in the Utilities Industry over the Credit Cycle

Coefficient Estimates in State 0

\begin{tabular}{lcc}
\hline \hline & $\Delta(B A A-A A)$ & $\Delta(B A A-A)$ \\
\hline Constant & -0.4101 & -0.1267 \\
$U_{t}$ & -0.0022 & -0.0187 \\
\hline \hline
\end{tabular}

Coefficient Estimates in State 1

\begin{tabular}{lcc}
\hline \hline & $\Delta(B A A-A A)$ & $\Delta(B A A-A)$ \\
\hline Constant & $3.4048^{* *}$ & $2.0887^{*}$ \\
$U_{t}$ & $0.4248^{*}$ & $0.3913^{* *}$ \\
\hline \hline
\end{tabular}

Variance Matrix in State 0

\begin{tabular}{lcc}
\hline \hline & $\Delta(B A A-A A)$ & $\Delta(B A A-A)$ \\
\hline$\triangle(B A A-A A)$ & $11.7413^{* * *}$ & $7.1060^{* * *}$ \\
$\triangle(B A A-A)$ & $7.1060^{* * *}$ & $7.7430^{* * *}$ \\
\hline \hline
\end{tabular}

Variance Matrix in State 1

\begin{tabular}{lcc}
\hline \hline & $\Delta(B A A-A A)$ & $\Delta(B A A-A)$ \\
\hline$\Delta(B A A-A A)$ & $196.8790 * * *$ & $124.5174 * * *$ \\
$\triangle(B A A-A)$ & $124.5174 * * *$ & $109.2570 * * *$ \\
\hline \hline
\end{tabular}

Transition Probability Matrix

\begin{tabular}{lcc}
\hline \hline & State 0 & State 1 \\
\hline State 0 & $0.9015^{* * *}$ & $0.1907^{* * *}$ \\
State 1 & $0.0985^{* * *}$ & $0.8093^{* * *}$ \\
\hline \hline
\end{tabular}

Note: This table presents the effect of unexpected changes in the Fed funds rate on changes in credit spreads in the utilities industry where the state variable is determined jointly by credit spreads in the utilities industry. The coefficient estimates are obtained from the MLE estimation of the Markov regime switching model in Equation (10) without any control variables. $U_{t}$ is the unexpected change in the Fed funds rate. State 0 corresponds to narrowing credit spreads in the utilities industry and State 1 corresponds to widening credit spreads. *** denotes significance at $1 \%$ confidence level, $* *$ denotes significance at $5 \%$ confidence level, $*$ denotes significance at $10 \%$ confidence level. 
Table 22: Correlations between Monetary Policy Cycle Indicators and Business Cycle Indicators

\begin{tabular}{lcccccc}
\hline \hline & $M C P I_{1, t}$ & $M C P I_{2, t}$ & $M C P I_{3, t}$ & $M C P I_{4, t}$ & $N E R_{t}$ & Prob $_{1, t}$ \\
\hline$M C P I_{1, t}$ & 1 & & & & & \\
$M C P I_{2, t}$ & 0.4436 & 1 & & & & \\
$M C P I_{3, t}$ & 0.4057 & 0.3220 & 1 & & & \\
$M C P I_{4, t}$ & 0.4220 & 0.9642 & 0.3116 & 1 & & \\
$N B E R_{t}$ & 0.4657 & 0.2831 & 0.3164 & 0.2927 & 1 & \\
$\operatorname{Prob}_{1, t}$ & 0.3942 & 0.1921 & 0.2440 & 0.2056 & 0.5155 & 1 \\
& & & & & & \\
\hline \hline
\end{tabular}

Note: This table presents the correlations between monetary policy cycle indicators and business cycle indicators. $M C P I_{1, t}$ and $M C P I_{2, t}$ are expansionary monetary policy indicators based on actual and expected changes in the Fed funds rate, respectively. $M C P I_{3, t}$ and $M C P I_{4, t}$ are expansionary monetary policy cycle indicators based on the reversal of actual and expected change in the Fed funds rate, respectively. $N B E R_{t}$ is a dummy variable that takes the value 1 in month $t$ if the economy is in a recession as defined by the NBER and zero otherwise. $\operatorname{Prob}_{1, t}$ is the real-time recession probability from the estimation of Equation (5). 
Table 23: The Effect of Unexpected Changes in the Fed Funds Rate on Credit Spreads over the Monetary Policy Cycle

$$
\triangle(B A A-A A A)
$$

\begin{tabular}{lcccc}
\hline \hline & $M C P I_{1, t}$ & $M C P I_{2, t}$ & $M C P I_{3, t}$ & $M C P I_{4, t}$ \\
\hline \multirow{3}{*}{ Constant } & & & & \\
$U_{t}$ & 0.3672 & -0.0048 & -0.0449 & -0.0060 \\
$M C P I_{t}$ & 0.2192 & -0.0292 & -0.0944 & -0.0292 \\
$U_{t} \times M C P I_{t}$ & $7.3560^{* * *}$ & 3.1193 & 2.4399 & 2.9793 \\
& 0.0097 & $0.2075^{*}$ & $0.2442^{* *}$ & $0.2061^{*}$ \\
\hline \hline
\end{tabular}

$$
\triangle(B A A-A A)
$$

\begin{tabular}{lcccc}
\hline \hline & $M C P I_{1, t}$ & $M C P I_{2, t}$ & $M C P I_{3, t}$ & $M C P I_{4, t}$ \\
\hline \multirow{2}{*}{ Constant } & 0.4447 & 0.1713 & 0.1055 & 0.1936 \\
$U_{t}$ & 0.1743 & -0.0149 & -0.0704 & -0.0138 \\
$M C P I_{t}$ & $4.1275^{* * *}$ & 1.8840 & 1.5541 & 1.7458 \\
$U_{t} \times M C P I_{t}$ & -0.0530 & 0.1342 & $0.1721^{*}$ & 0.1319 \\
& & & & \\
\hline \hline
\end{tabular}

$\triangle(B A A-A)$

\begin{tabular}{lcccc}
\hline \hline & $M C P I_{1, t}$ & $M C P I_{2, t}$ & $M C P I_{3, t}$ & $M C P I_{4, t}$ \\
\hline & & & & \\
Constant & 0.1799 & 0.2519 & -0.1919 & 0.2605 \\
$U_{t}$ & 0.0506 & -0.0317 & -0.0585 & -0.0312 \\
$M C P I_{t}$ & $3.1605^{* *}$ & 0.6924 & 1.3757 & 0.6409 \\
$U_{t} \times M C P I_{t}$ & 0.0411 & 0.0966 & 0.1066 & 0.0957
\end{tabular}

Note: This table presents the effect of unexpected changes in the Fed funds rate on changes in credit spreads over expansionary monetary policy cycles. $M C P I_{1, t}$ and $M C P I_{2, t}$ are expansionary monetary policy indicators based on actual and expected changes in the Fed funds rate. $M C P I_{3, t}$ and $M C P I_{4, t}$ are expansionary monetary policy cycle indicators based on the reversal of actual or expected change in the Fed funds rate as discussed in the text. The coefficients are estimated via OLS with HAC standard errors. *** denotes significance at $1 \%$ confidence level, $* *$ denotes significance at $5 \%$ confidence level, $*$ denotes significance at $10 \%$ confidence level. 
Table 24: The Effect of Monetary Policy on Credit Spreads in a Joint Framework

Coefficient Estimates in State 0

\begin{tabular}{lccccc}
\hline \hline & $\Delta(B A A-A A A)$ & $\Delta(B A A-A A)$ & $\Delta(B A A-A)$ & $\Delta \ln (I P)$ & $A_{t}$ \\
\hline Constant & $-1.0943^{* * *}$ & $-1.0978^{* * *}$ & $-0.7315^{* * *}$ & $0.3200^{* * *}$ & $4.2508^{* * *}$ \\
$U_{t}$ & $-0.0535^{*}$ & -0.0387 & $-0.0711^{* * *}$ & 0.0022 & $0.9633^{* * *}$ \\
\hline \hline
\end{tabular}

Coefficient Estimates in State 1

\begin{tabular}{lccccc}
\hline \hline & $\Delta(B A A-A A A)$ & $\Delta(B A A-A A)$ & $\Delta(B A A-A)$ & $\Delta \ln (I P)$ & $A_{t}$ \\
\hline Constant & $6.4622^{* * *}$ & $5.4175^{* * *}$ & $3.3220^{* * *}$ & $-0.1754 *$ & $-11.3035^{* * *}$ \\
$U_{t}$ & $0.3081^{* *}$ & $0.2107^{*}$ & 0.1536 & -0.0037 & $1.2210^{* * *}$ \\
\hline \hline
\end{tabular}

Variances

\begin{tabular}{lcc}
\hline \hline & Variances in State 0 & Variances in State 1 \\
\hline$\triangle(B A A-A A A)$ & $11.6774 * * *$ & $225.9087 * * *$ \\
$\Delta(B A A-A A)$ & $9.4037^{* * *}$ & $159.3405^{* * *}$ \\
$\Delta(B A A-A)$ & $8.3517 * * *$ & $93.3265^{* * *}$ \\
$\Delta \ln (I P)$ & $0.2456 * * * .5765^{* * *}$ \\
$A_{t}$ & $177.5167 * * *$ & $808.4334 * * *$ \\
\hline \hline
\end{tabular}

Transition Probability Matrix

\begin{tabular}{lcc}
\hline \hline & State 0 & State 1 \\
\hline State 0 & $0.8381 * * *$ & $0.3528 * * *$ \\
State 1 & $0.1619 * * *$ & $0.6472 * * *$ \\
\hline \hline
\end{tabular}

Note: This table presents the effect of unexpected changes in the Fed funds rate on changes in credit spreads in a framework where the state variable is determined jointly by credit spreads, growth rate of industrial production and actual changes in the Fed funds rate. The coefficient estimates are obtained from the MLE estimation of the Markov regime switching model in Equation (13). State 0 corresponds to good times where credit spreads narrow, the industrial production grows and the Fed follows a contractionary monetary policy. State 1 corresponds to bad times where credit spreads widen, the industrial production decreases and the Fed follows an expansionary monetary policy. $I P_{t}$ is the level of industrial production index and $A_{t}$ is the actual change in the Fed funds rate. $* * *$ denotes significance at $1 \%$ confidence level, $* *$ denotes significance at $5 \%$ confidence level, $*$ denotes significance at $10 \%$ confidence level. 
Table 25: The Effect of Unexpected Changes in the Fed Funds Rate on Market Participants' Inflation Expectations

Michigan Inflation Expectations Conference Board Inflation Expectations

$\begin{array}{lcc}\text { Constant } & -0.0685 & 0.0429 \\ \pi_{t-1} & 0.8396 * * * & 0.9322 * * * \\ U_{t} & -1.3392 * * * & -0.6491 \\ \left(1-\operatorname{Prob}_{1, t}\right) & 0.6150^{* * *} & 0.3102 * * * \\ U_{t} \times\left(1-\operatorname{Prob}_{1, t}\right) & 1.6361 * * * & 0.9173 *\end{array}$

Note: This table presents the effect of unexpected changes in the Fed funds rate on the market participants' inflation expectations over the business cycle. $\pi_{t}$ represents the market participants' inflation expectations measured by either the University of Michigan or the Conference Board Surveys. $U_{t}$ is the unexpected change in the Fed funds rate and Prob $b_{1, t}$ is the real-time recession probability from the estimation of Equation (5). The coefficients are estimated via OLS with HAC standard errors. $* * *$ denotes significance at $1 \%$ confidence level, $* *$ denotes significance at $5 \%$ confidence level, * denotes significance at $10 \%$ confidence level. 